\title{
Modeling an Active and Passive Thermal Protection System for a Hypersonic Vehicle
}

\author{
Christopher D. Marley* and James F. Driscoll ${ }^{\dagger}$ \\ University of Michigan, Ann Arbor, Michigan, 48109, U.S.A.
}

\begin{abstract}
Efficient aerodynamic heating and thermal protection system models are added to MASIV, a reduced-order model of a generic scramjet-powered vehicle. The MASIV code was selected over similar reduced-order models because of its advanced combustion model, as heat addition to the combustor walls is often the largest source of heating in hypersonic air-breathing vehicles. The thermal protection system consists of passive insulation and active cooling with the liquid hydrogen fuel acting as the cooling agent. Temperatures within the passive thermal protection system are shown over time at verious trimmed flight conditions. High temperatures within the combustor walls reveal the need for active cooling. The results show important trade-offs for design and optimization purposes.
\end{abstract}

\section{Nomenclature}

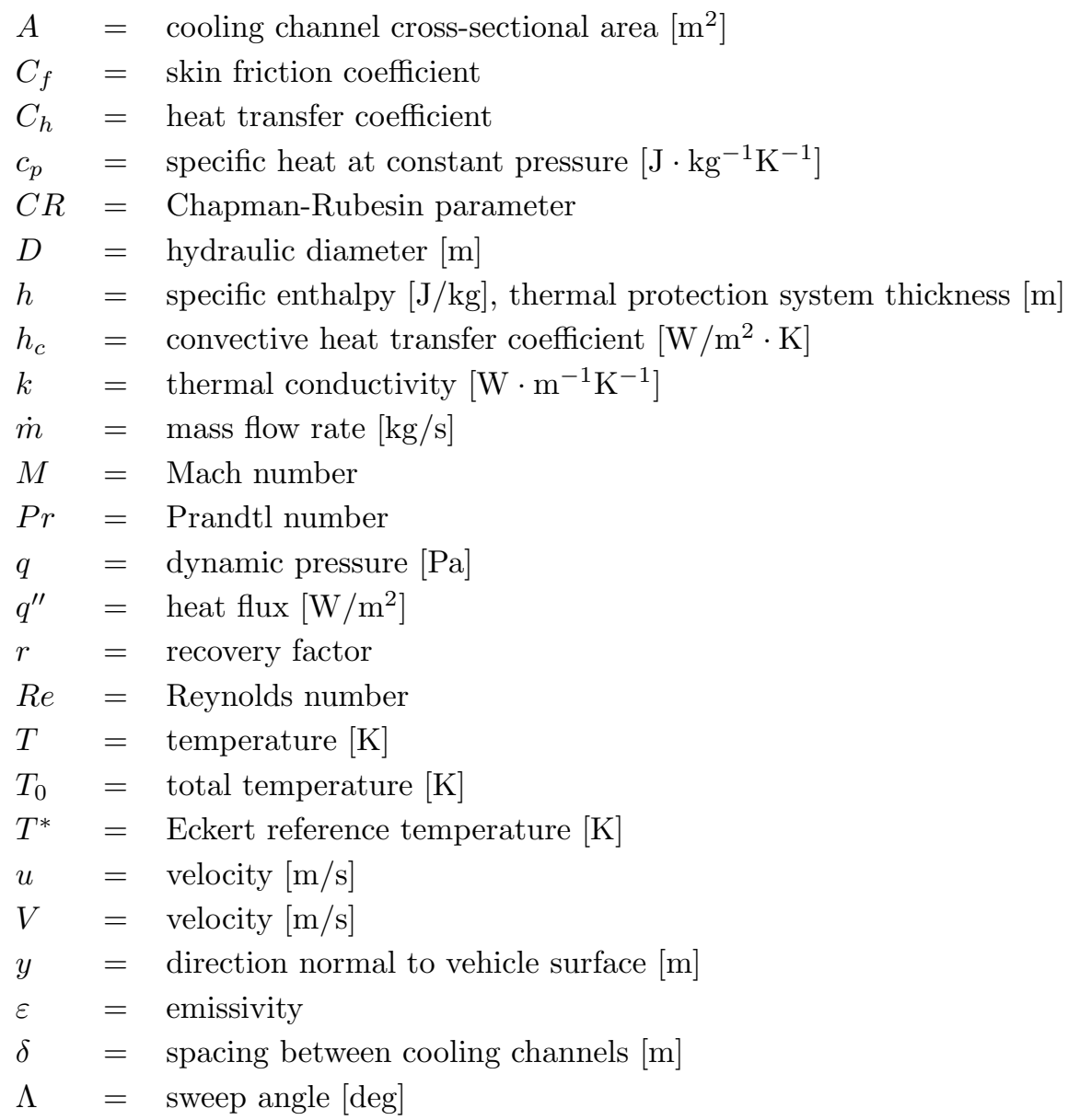

*Graduate Research Assistant, Department of Aerospace Engineering, AIAA Member, cmarley@umich.edu.

${ }^{\dagger}$ Professor, Department of Aerospace Engineering, AIAA Fellow, jamesfd@umich.edu. 


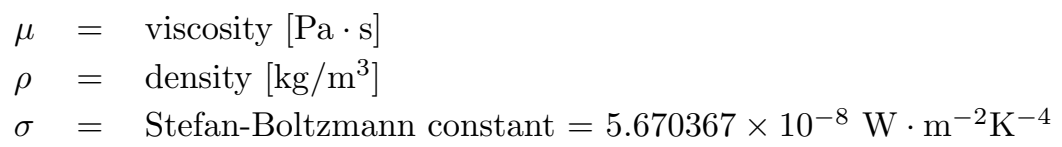

\begin{tabular}{|c|c|c|}
\hline \multicolumn{2}{|c|}{ Subscripts } & \\
\hline$a w$ & $=$ & adiabatic wall \\
\hline$c$ & $=$ & cooling channel \\
\hline conv & $=$ & convection \\
\hline cyl & $=$ & cylinder \\
\hline$e$ & $=$ & external to boundary layer \\
\hline$F$ & $=$ & fuel \\
\hline$H E X$ & $=$ & heat exchanger \\
\hline lam & $=$ & laminar \\
\hline$L E$ & $=$ & leading edge \\
\hline $\mathrm{rad}$ & $=$ & radiation \\
\hline$s$ & $=$ & stagnation point \\
\hline turb & $=$ & turbulent \\
\hline$w$ & $=$ & wall \\
\hline$w c$ & $=$ & cooling channel wall \\
\hline$x$ & $=$ & distance from leading edge \\
\hline$\infty$ & $=$ & free-stream \\
\hline
\end{tabular}

\section{Introduction}

Heating is a limiting factor in the operation of hypersonic vehicles, as described in Refs. 1-10. The large kinetic energy of the free-stream is thermalized as the flow velocity slows near the surface, particularly in the stagnation regions, causing large heat flux into the skin and structure. In addition, in the case of scramjetpowered hypersonic vehicles, there is a large heat flux into the vehicle surface surrounding the engine. A Thermal Protection System (TPS) is necessary to absorb the heat energy and prevent the skin and structure from reaching its failure temperature. Typically, the TPS will consist of passive layers of insulating material, along with an active cooling system in the regions of highest heat flux near the leading edges and around the engine.

Due to the integrated nature of the heating effects, a reduced-order model (as opposed to a high-fidelity, CFD based model) of a hypersonic vehicle is required to design and optimize the thermal protection system. Several reduced-order models of hypersonic vehicles exist, including a code developed by Johnson et al. ${ }^{1}$ and one developed at AFRL by Bolender and Doman. ${ }^{2}$ For this work, MASIV (Michigan-AFRL Scramjet In Vehicle) is used. Figure 1 shows the aerodynamic mesh for the MAX-1 geometry used in this study. One advantage of MASIV over similar codes is the propulsion model, which has an advanced mixing model to better simulate combustion heat release as well as a real-gas model which results in more realistic temperature values within the combustor. The passive thermal protection system added to MASIV is separated into three regions: 1) external surface, 2) propulsion system flow-path, and 3) leading edge (or nose) region, as shown in Fig. 2.

For the active cooling system, fuel usually acts as the cooling agent in the heat exchangers. ${ }^{8,9,11-13}$ Recent work by Doman ${ }^{10,14}$ investigates the system-level architecture of an active cooling system on a generic, turbojet-powered aircraft. Two main types of configurations for the active cooling system exist. In one configuration, all the fuel flowing through the heat exchanger is expelled into the combustor as shown in Fig. 3 a). This configuration is inflexible and can provide insufficient cooling if the required heat exchanger fuel flow rate exceeds the required combustor fuel flow rate. In Doman's work, the fuel through the heat exchanger is partially recirculated back into the fuel tank (after passing through a second heat exchanger to partially cool the fuel) allowing for greater flexibility as shown in Fig. 3 b). However, as the fuel absorbs heat and is recirculated back into the fuel tank, the fuel temperature rises until a maximum allowable temperature is reached. 


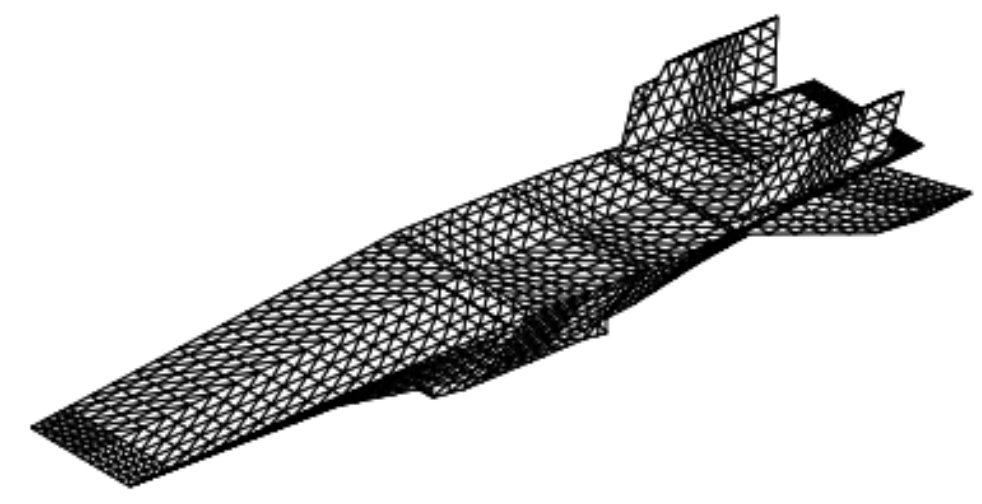

Figure 1. Geometry and aerodynamic mesh for MAX-1 vehicle.

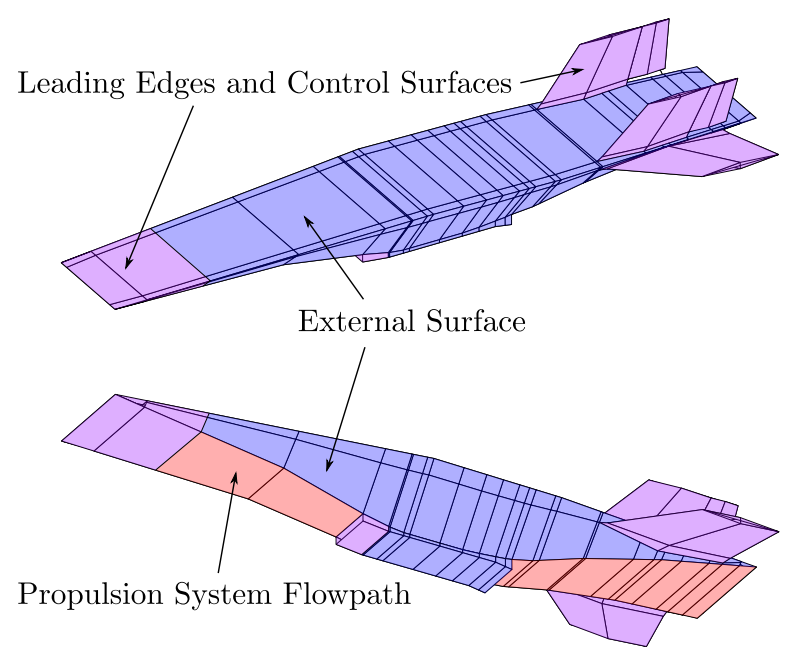

Figure 2. Schematic showing the different passive TPS regions of the MAX-1 vehicle. The regions include: Leading Edges, Control Surfaces, Propulsion System Flow-path, and External Surface.

The following section reviews recent efforts to model aerodynamic heating and thermal protection in high-speed vehicles. The studies focus on reduced-order models for design and optimization purposes and examples of both active and passive cooling are presented. After the summary of previous related research, the specific objectives of the current study are discussed. Next is a review of heat transfer and TPS modeling techniques, followed by specifics of the modeling additions to MASIV. Aerodynamic heating due to convection is modeled for both internal and external flow-paths. Heating through the passive insulation layers is modeled as unsteady, one-dimensional conduction. Modeling of the active cooling system is also presented. Results from each of the main model subsystems (i.e. aero-heating, passive TPS, and active cooling) are presented. Finally, this paper concludes with a summary of the information gathered from the subsystems relevant for design considerations.

\section{Previous Related Research}

A number of reduced-order models of scramjet-powered hypersonic cruise vehicles, intended for design and optimization purposes, have been developed in recent years. Besides the MASIV model used in the current study, similar models include the codes developed by Starkey et al. in Ref. 15 and by Zhang et al. in 
a) No Fuel Recirculation Back Into Fuel Tank

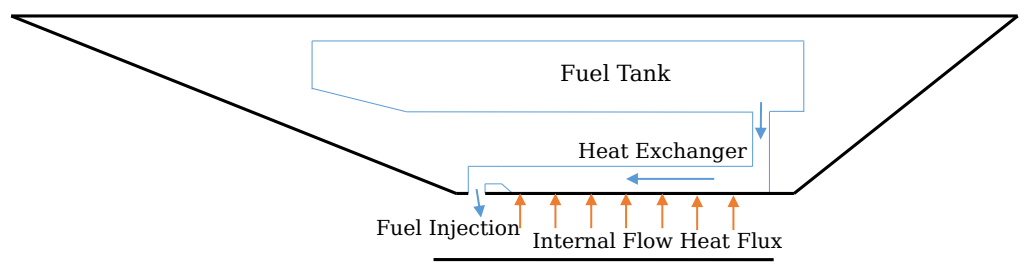

b) Fuel Recirculated Back Into Fuel Tank

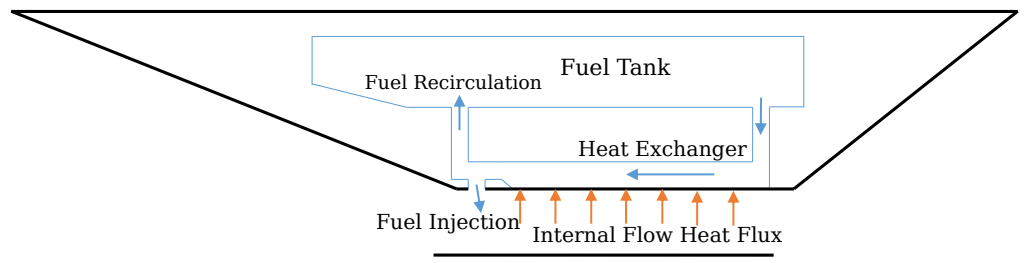

Figure 3. Schematic of active cooling system architecture for generic waverider hypersonic vehicle: a) no fuel recirculation and b) with fuel recirculation. In this model, the heat exchanger cools only the inter flow walls.

Ref. 6. One similarity between these codes is that they attempt to model all the major, relevant subsystems (including the vehicle geometry and external aerodynamics, the scramjet engine, weight estimations, and the vehicle dynamics and trim) efficiently and parametrically to enable optimization. The codes are unique, however, in that they each emphasize different design aspects. The code by Starkey et al. for example includes an aeroelastic analysis tool, which the other models lack; whereas the MASIV code, initially intended for propulsion system integration studies, includes an advanced engine model. This section will review past thermal management related reduced-order modeling efforts, including efforts to model heat transfer and TPS systems within full models of scramjet-powered vehicles such as those in Refs. 15 and 6 . Also reviewed in this section are studies more limited in scope, focusing on passive cooling at a vehicle stagnation point only or active cooling around the engine only.

\section{A. Heat Transfer and TPS Modeling in Current Reduced-Order Scramjet Vehicle Models}

Recently developed reduced-order models for hypersonic cruise vehicles have incorporated some aspects important to thermal management. Starkey et al. ${ }^{15}$ use the boundary layer equations to calculate the convective heat flux to the vehicle external surface (which excludes the engine flow-path) for a given flight trajectory and wall temperature. Completely separate from this heat flux calculation is the passive TPS optimization. With the convective heat flux already calculated for each point along the given trajectory, the heat flux is then used as a boundary condition to calculate the one-dimensional conduction through the TPS surface. A gradient-based optimization technique is then used to find the minimum TPS thickness to ensure the TPS material does not exceed failure temperature at any point along the trajectory. It is important to note that the convective heat flux calculation is highly dependent on the surface wall temperature, but these are not coupled in Starkey's code, potentially leading to high inaccuracies.

Zhang et al. ${ }^{6}$ use the flat plate boundary layer theory, along with Reynolds analogy, to calculate the convective heat flux over a scramjet-powered hypersonic cruise vehicle. Heat transfer around the scramjet engine is neglected. Unlike the model by Starkey et al., which computes the distributed convective heat flux on the external surface, the model by Zhang et al. computes the convective heat flux at the vehicle stagnation point and along the vehicle center-line only. Zhang et al. also model the radiative cooling at the surface using the wall temperature and an appropriate emissivity for the surface material. Instead of calculating the wall temperature by modeling conduction through the surface (coupled with the convective heat flux boundary 
condition), the wall temperature is obtained by assuming the convective heat flux and radiative cooling are in equilibrium, which is not necessarily true. Multiple vehicle parameters are optimized simultaneously including the cruise range. The only TPS related optimization includes minimizing the stagnation point wall temperature.

While hypersonic cruise vehicle models have incorporated some aspects of heat transfer and TPS modeling, they are still lacking in other aspects. The code by Starkey et al., for example, neglects the stagnation point heating and radiative cooling. Also, the two codes reviewed in this section both neglect active cooling and heat transfer around the engine. Both of these studies also neglect transition from laminar to turbulent flow, which effects the convective heat flux. The TPS model added to MASIV includes both active and passive cooling and models stagnation point heating, convective heating around the vehicle and engine, and radiative cooling.

\section{B. Passive TPS Design and Optimization Studies}

Aerodynamic heating is critical to all types of hypersonic vehicles (not just scramjet-powered vehicles), and multiple studies have researched design and optimization considering aerodynamic heating and passive thermal protection systems. In a 2015 study, Rizvi et al. ${ }^{3}$ perform trajectory optimization for hypersonic boost-glide vehicles subject to a maximum heat rate limit. Several classes of vehicles are considered for the unpowered glide phase. Rizvi et al. state that the maximum heat rate is likely to occur at the vehicle nose or wing/fin leading edge stagnation point. The stagnation point heat rate at the nose is calculated using an engineering correlation which takes into account the nose curvature. The wing/fin leading edge stagnation point heat rate is calculated using a similar engineering correlation which takes into account both the leading edge curvature and sweep angle. A heat rate constraint of $4 \mathrm{MW} / \mathrm{m}^{2}$ is imposed for optimization. The imposed heat rate limit corresponds to a maximum temperature limit of $2900 \mathrm{~K}$ (the temperature limit for reinforced carbon-carbon material). The maximum heat rate constraint calculation assumes the convective flux and radiative cooling are in equilibrium, which is not necessarily true. The freeparameters optimized include the burn-out angle, burn-out altitude, and burn-out speed. The optimization objective is to maximize the the projectile down range and cross range distances.

In another study, Johnson et al. ${ }^{1}$ optimize the geometry of planetary entry vehicles to minimize stagnation point heat flux and maximize lift-to-drag ratio. Only the heat flux at the stagnation point was considered; the heat load (the integrated heat flux over time) was not considered. The total stagnation point heat flux includes both convection and radiation into the vehicle. The convective heat flux was calculated using a correlation similar to the relationship used by Rizvi et al. ${ }^{3}$ Also considered in the study by Johnson et al. is the radiation heat flux into the vehicle. The Mach number ranges from $M_{\infty}=30-50$, much higher than the present study; the current study considers only radiative cooling from the high temperature vehicle surface to the air, and not radiation from the air to the vehicle surface. The free-parameters optimized include vehicle cross section and axial profile; three classes of axial profiles considered include spherical segment, spherically blunted cone and power law. In the study by Johnson et al., for a fixed trajectory, a gradient based optimization method (the modified method of feasible directions) is used to find the optimal geometry which provides the lowest stagnation point heat flux.

Tormo and Serghides ${ }^{5}$ present a preliminary design methodology for a reusable space plane considering vehicle heating constraints. An empirical model is used to calculate aerodynamic heating at the stagnation point only. However, unlike the studies by Rizvi et al. ${ }^{3}$ and Johnson et al., ${ }^{1}$ Tormo and Serghides also compute the surface temperature at the stagnation point by modeling energy accumulation inside the nose surface (similar to the approach used in the current study as described in Part B of Section V). The radiative cooling at the stagnation point is also calculated based on the stagnation point surface temperature and emissivity. The aerodynamic heating model is validated by comparing results to X-15 flight test data. Tormo and Serghides consider two preliminary design aspects: initial sizing and trajectory. An estimation of the required thickness of a single layer TPS (at the stagnation point only) is calculated by modeling onedimensional conduction into the surface for selected material properties. The energy-state approximation method is used to optimize the trajectory. A contour of the vehicle specific energy is generated over a range of Mach numbers and altitudes. A minimum and maximum dynamic pressure is specified. Three optimal trajectories are calculated: minimum time, minimum temperature at the stagnation point, and minimum heat-load at the stagnation point. The minimum time trajectory follows the maximum dynamic pressure constraint. The minimum temperature and minimum heat-load trajectories occur at lower dynamic pressures and are nearly identical to each other. 
In a study by Gogu et al. ${ }^{7}$ on aeroassisted orbital transfer vehicles, the authors combine trajectory optimization with TPS optimization to minimize the combined fuel and TPS weight. A simplified empirical correlation is used to calculate the stagnation point heat rate; the correlation is a function of the freestream density and velocity only (neglecting the temperature difference between the wall- and recoverytemperatures). Radiation cooling is also neglected. To estimate heat flux over the entire vehicle based on the stagnation point heating, an empirical, non-dimensionalized heat flux distribution along the surface in the longitudinal direction is applied (the distribution is assumed uniform in the lateral direction). The empirical heat flux distribution assumes the flow is laminar over the entire vehicle. The TPS comprises of an ablation region near the leading edge, where heat flux is highest, and a permanent region composed of LI-900 insulation where the heating is less intense. The minimum TPS thickness required is found by modeling one-dimensional conduction through the surface. During optimization, a range of stagnation point heating rate constraints are specified and an optimal trajectory which minimizes fuel consumption is found for each constraint. The TPS thickness (and hence mass) is then found for each of these optimized trajectories. The final optimized solution is the trajectory with the minimum combined fuel and TPS weight.

Bolender and Doman ${ }^{2}$ study the impact of aerodynamic heating to the structure of a X-43 type waverider. A detailed model of the passive thermal protection layers is presented and the TPS is analyzed at a single point on the surface. The convective heat flux to the surface is not calculated, but rather is specified to be a representative value, and remains constant during cruise. Radiative cooling at the vehicle surface is computed. Unsteady, one-dimensional conduction through the surface is modeled to capture the change in temperate within the TPS over time. The results show that heat transfer increases the vehicle flexibility and causes changes in the bending moment that alter the vehicle stability.

\section{Active TPS Design and Optimization Studies}

In Doman's ${ }^{10,14}$ research on the system-level architecture of active cooling in high-speed vehicles, the heat flux from the engine to the cooling channel is a single, fixed value (i.e. the heat flux is not distributed along the engine and does not change with flight conditions). A more detailed engine heat flux and active cooling model is desired for the current study and several papers have investigated modeling and design of active cooling in scramjet engines.

Bao et al. ${ }^{8}$ model an active cooling system for a scramjet engine utilizing hydrocarbon fuel. Only the scramjet is considered, not the entire vehicle. The distributed convective heat flux to the engine walls is prescribed based on experimental data for a scramjet engine at Mach 6, and the heat flux value remains fixed. The hydrocarbon fuel is at supercritical pressure, where it is noted that the physical properties (i.e. density, specific heat and thermal conductivity) can change substantially. Bao et al. model the change in fuel chemistry to capture change in physical properties as the fuel is heated. Convective heat transfer to the heat exchanger is modeled using an engineering correlation for the Nusselt number. The correlation is a function of the cooling channel hydraulic diameter and fuel flow rate along with the physical propertied of the fuel. Bao et al. optimize the coolant flow rate and show the improvements provided by the endothermic chemistry of their fuel. In a similar study from the same research group, Zhang et al. ${ }^{9}$ consider the design aspect of a passive insulation layer sandwiched between the cooling channel and the engine wall. Unlike Bao, ${ }^{8}$ Zhang ${ }^{9}$ uses hydrogen fuel; however, again only the scramjet engine is modeled.

The current model incorporates an active cooling model with the complete vehicle heat transfer calculations and passive thermal protection system model for comprehensive design and analysis. Also, the current model utilizes hydrogen fuel at supercritical conditions, which the physical properties, similar to hydrocarbon fuel at supercritical conditions, can change rapidly and it is important to model changes in the those properties.

\section{Summary of Past Related Research}

Table 1 summarizes several of the reduced-order models that were used to compute heating rates and model the thermal protection system for hypersonic vehicles. The table shows that only two other studies besides the present work report heating rates of an entire vehicle (external surface). The others use an empirical formula for the heating rate at the forward stagnation point or impose a representative heating rate along the engine sidewall or at single point on the surface. Passive cooling is used in most of the studies; it consists of a layer of insulation surrounded by a metal skin. Active cooling only is considered in a few cases by flowing liquid fuel past the combustor wall. 
The table indicates that various quantities have been optimized, including the trajectory, vehicle stability, cruise range and coolant flow rates. Three previous models of hypersonic vehicles have optimized the thermal protection system of a hypersonic vehicle, while applying heat transfer constraints (Rizvi, et al., ${ }^{3,4}$ Johnson et al. ${ }^{1}$ and Tormo and Serghides $\left.{ }^{5}\right)$. These three studies showed how much the insulation layer thickness must be increased to prevent the wall temperature from exceeding a maximum value before the end of some desired flight time. Three other studies have computed heat transfer but did not optimize the TPS; they are by Bolender and Doman, ${ }^{2}$ Zhang et al. ${ }^{6}$ and Gogu et al. ${ }^{7}$

In all six of these previous studies the heat transfer was computed only at one location (the forward stagnation point) and only a passive TPS was considered; active cooling using the liquid fuel was not considered. Some other studies did not consider an entire vehicle, but only computed the heat transfer from a scramjet engine alone (Bao et al., ${ }^{8}$ Zhang et al. ${ }^{9}$ and Doman ${ }^{10}$ ). They did consider active cooling of the engine by the liquid fuel.

The above literature review indicates that no previous study has solved the comprehensive problem of optimizing both an active and a passive TPS for an entire trimmed hypersonic vehicle. Such a comprehensive problem is investigated in the present work.

Table 1. Previous reduced-order models of heating rates and the thermal protection system, compared to the present work.

\begin{tabular}{|c|c|c|c|c|c|c|c|}
\hline Author(s) & $\begin{array}{l}\text { Optimization } \\
\text { Performed? }\end{array}$ & $\begin{array}{l}\text { Heating Rate } \\
\text { Computed For: }\end{array}$ & $\begin{array}{c}\text { Passive or } \\
\text { Active Cooling }\end{array}$ & $\begin{array}{l}\text { Vehicle } \\
\text { Trimmed? }\end{array}$ & Trajectory & Power Plant & Notes \\
\hline Present work & Yes & Entire vehicle & $\begin{array}{l}\text { Both active } \\
\text { and passive }\end{array}$ & Yes & $\begin{array}{l}\text { Ascent/ } \\
\text { Cruise }\end{array}$ & $\begin{array}{l}\mathrm{H}_{2} \text { powered } \\
\text { scramjet }\end{array}$ & - \\
\hline Rizvi et al. ${ }^{3}$ & Yes & $\begin{array}{l}\text { Stagnation } \\
\text { point only }\end{array}$ & Passive only & Yes & $\begin{array}{l}\text { Ascent/ } \\
\text { Descent }\end{array}$ & None & $\begin{array}{l}\text { Trajectory optimized subject to max heat } \\
\text { rate (instead of max temperature) }\end{array}$ \\
\hline Johnson et al. ${ }^{1}$ & Yes & $\begin{array}{l}\text { Stagnation } \\
\text { point only }\end{array}$ & Passive only & $\mathrm{n} / \mathrm{a}$ & Descent & None & $\begin{array}{l}\text { Blunt-body reentry vehicle geometry } \\
\text { optimized for minimum stagnation point heat } \\
\text { flux (heat load not considered) }\end{array}$ \\
\hline $\begin{array}{l}\text { Tormo and } \\
\text { Serghides }^{5}\end{array}$ & Yes & $\begin{array}{l}\text { Stagnation } \\
\text { point only }\end{array}$ & Passive only & Yes & $\begin{array}{l}\text { Ascent/ } \\
\text { Descent }\end{array}$ & Rocket & $\begin{array}{l}\text { Trajectory optimized for minimum: time, } \\
\text { temperature, and heat-load }\end{array}$ \\
\hline Starkey et al. ${ }^{15}$ & Yes & $\begin{array}{l}\text { External } \\
\text { Surface }\end{array}$ & Passive only & Yes & Ascent & Scramjet & $\begin{array}{l}\text { TPS thickness optimized. External heat flux } \\
\text { and internal conduction calculations are } \\
\text { decoupled }\end{array}$ \\
\hline Gogu et al. ${ }^{7}$ & Yes & $\begin{array}{l}\text { Stagnation } \\
\text { point only }\end{array}$ & Passive only & Yes & $\begin{array}{l}\text { Orbital } \\
\text { transfer }\end{array}$ & Rocket & $\begin{array}{l}\text { Heating computed at stagnation point only } \\
\text { but that value is extrapolated to estimate } \\
\text { heating over entire vehicle. Trajectory and } \\
\text { TPS thickness optimized. }\end{array}$ \\
\hline Zhang, D. et al. ${ }^{6}$ & Yes & Entire vehicle & Passive only & Yes & Cruise & Scramjet & $\begin{array}{l}\text { Multiple parameters optimized } \\
\text { simultaneously including cruise range. Only } \\
\text { TPS related optimization includes } \\
\text { minimizing stagnation point wall } \\
\text { temperature. }\end{array}$ \\
\hline Bao et al. ${ }^{8}$ & No & Engine only & Active only & No & Cruise & $\begin{array}{l}\text { Hydrocarbon } \\
\text { scramjet }\end{array}$ & $\begin{array}{l}\text { Endothermic fuel used as heat sink for two } \\
\text { representative operating conditions. No } \\
\text { optimization performed. }\end{array}$ \\
\hline Zhang, C. et al. ${ }^{9}$ & No & Engine only & $\begin{array}{l}\text { Both active } \\
\text { and passive }\end{array}$ & No & Cruise & $\begin{array}{l}\text { Hydrocarbon } \\
\text { scramjet }\end{array}$ & $\begin{array}{l}\text { Passive TPS (along with the active cooling) } \\
\text { considered in engine only }\end{array}$ \\
\hline $\begin{array}{l}\text { Bolender and } \\
\text { Doman }^{2}\end{array}$ & No & $\begin{array}{l}\text { Convective heat } \\
\text { flux specified }\end{array}$ & Passive only & No & Cruise & Scramjet & $\begin{array}{l}\text { Effects of heating on vehicle structure are } \\
\text { studied }\end{array}$ \\
\hline $\operatorname{Doman}^{10}$ & Yes & $\begin{array}{l}\text { Heating in } \\
\text { engine specified }\end{array}$ & Active only & No & Cruise & Turbojet & $\begin{array}{l}\text { Only active cooling is considered; various fuel } \\
\text { tank architectures studied }\end{array}$ \\
\hline
\end{tabular}

\section{E. Previous Development of MASIV Code}

The MASIV code is a Reduced Order Model (ROM) developed originally to trim the the MAX-1 vehicle (shown in Fig. 1) at each point along a trajectory. ${ }^{16-22}$ Consider that a vehicle may be trimmed at each of fifty altitudes during an ascent; at each altitude ten values of angle of attack are selected to find the one that balances forces and moments. If ten trajectories are considered, this means that all forces, the engine thrust, and heat loads must be computed for 5,000 cases. This number is too large to consider a high-fidelity CFD approach, hence the need for a reduced-order model such as MASIV. One run of a ROM requires less than a few seconds on a single processor because large lookup tables (of the finite rate chemistry in this case) are computed apriori. ROMs provides a first-look at a large multi-dimensional parameter space; then interesting 
subregions can be investigated in more detail with CFD. Thus ROMs do not compete with high-fidelity CFD but can be used along with CFD to zero in on interesting new trends.

The MASIV code has been used to determine the optimum trajectory that minimizes the fuel required for ascent. ${ }^{16}$ It also was modified to compute the ram-scram transition boundary ${ }^{20}$ and the operability limit associated with engine unstart. ${ }^{17}$ However, in all of the previous studies that used MASIV, none considered heat transfer or a thermal protection system. The MAX-1 vehicle is similar to the AFRL generic aircraft of Bolender and Doman. ${ }^{23}$ It has a length of $29.1 \mathrm{~m}$ and the fuselage has a maximum width of $6 \mathrm{~m}$. The width of the dual mode ramjet-scramjet engine is $2.143 \mathrm{~m}$. The engine inlet is rectangular with a sufficiently large aspect ratio of 15.3 such that it can be considered to be two-dimensional. The isolator is $1.38 \mathrm{~m}$ long and is followed by the constant area portion of the combustor that is $0.90 \mathrm{~m}$ long; both have a cross section of $0.14 \mathrm{~m}$ high by $2.143 \mathrm{~m}$ wide. The second part of the combustor is $0.62 \mathrm{~m}$ long and its upper wall diverges at 4 degrees.

The MASIV reduced-order model has three subroutines to compute body forces, engine thrust and the trim angle of attack. Body forces are determined by the panel method, which also considers forces on elevons, ailerons and the rudder. Viscous forces were estimated using hypersonic flat-plate boundary layer skin friction formulas. The engine thrust code computes shock wave interactions in the inlet; it also computes finite rate chemistry in the combustor.

The engine inlet code employs the method of characteristics to determine wave interactions and compute the static pressure rise and the stagnation pressure loss in the inlet. It assumes that the engine flow is 2-D, wall deflection angles are small, no flow separation occurs, and that that strong shock/boundary layer interactions do not occur. The inlet model agrees with full CFD to within $6 \%$ for the simple inlet geometries considered. ${ }^{16}$ The combustor is simulated by a 1-D air flow with heat addition to a variable area duct. Mixing and reactions are simulated using a 3-D sub-model; empirical formulas are used to compute the fuel concentrations within a 3-D fuel jet burning in an air cross-flow. Finite rate chemistry is tabulated into lookup tables using a standard assumed PDF turbulent combustion model. Then the 3-D heat release is integrated over the combustor lateral dimensions for the 30 fuel jets to obtain a 1-D profile of heat release rate.

The trim model in MASIV has been described in Ref. 16. Standard flight dynamics analysis was applied to cast the equations that balance the forces and moments into the following form:

$$
\dot{x}=f(x, u)
$$

Here, $x$ is a vector of state variables, and $u$ is a vector of control variables, given by:

$$
\begin{gathered}
x=\left[\begin{array}{llllllllllll}
L & \lambda & h & V & \gamma & \sigma & \phi & \alpha & \beta & P & Q & R
\end{array}\right] \\
u=\left[\begin{array}{lllll}
E R & \delta_{e} & \delta_{a} & \delta_{r}
\end{array}\right]^{T}
\end{gathered}
$$

$L$ is latitude, $\lambda$ is longitude, $h$ is the altitude and $V$ is flight velocity; all four are specified before trim is computed. Angles $\gamma, \sigma, \phi$, and $\beta$ are flight path, velocity heading, roll and sideslip angles, while $\alpha$ is the angle of attack. $P, Q$, and $R$ are the roll, pitch and yaw rates. $E R$ is the fuel-air equivalence ratio while $\delta_{e}$ ,$\delta_{a}$ and $\delta_{r}$ are the deflection angles of the elevon, aileron and rudder. The weight of the vehicle decreases as fuel is consumed, and the desired acceleration is specified. Trim is achieved by selecting typically ten values of angle of attack to determine which value of $\alpha$ satisfies Eq. 1. Trimming the vehicle at each point along its trajectory is important because this determines the fuel-air equivalence ratio $(E R)$ required to provide

the correct thrust. It also determines the angle of attack required for lift to balance weight. The angle of attack controls the total drag as well as the air entrained into the engine.

\section{New Contributions of the Present Study}

This study will document the modeling features added to MASIV to comprehensively analyze thermal management in a hydrogen-fueled scramjet vehicle. The modeling additions include:

- Passive thermal protection system:

- Convective heat transfer to external surface (laminar and turbulent) 
- Stagnation point heating

- Radiative cooling

- Unsteady 1D conduction through walls

- TPS sizing and material properties

- Active thermal protection system:

- Convective heat transfer to engine walls

- Super-critical hydrogen-fuel heat exchanger model

- Heat exchanger geometry and operating conditions

- Recirculation of heat exchanger fuel to fuel tank

With the comprehensive thermal management model added to MASIV, this paper will demonstrate some of the limitations of Doman's simple model (i.e. non-constant engine heat flux). Other studies also assume constant heat flux values (like Bolender and Doman and Zhang) during cruise. During cruise however, as fuel is depleted, reducing the weight, the vehicles must be re-trimmed, changing the flight conditions and hence the heat flux will change.

Several of the reviewed papers assume that the radiation cooling is equal to the convective heat flux (i.e. Rizv, Johnson). There is no guarantee, even during cruise, that the convective heat flux will be in equilibrium with the radiative cooling; the wall temperature can be higher or lower than the calculated value. This paper will demonstrate that the condition of equilibrium between the convective heat flux and radiative cooling is not always appropriate. Also, while equilibrium might be the ultimate goal for cruise vehicles, simply specifying equilibrium does not provide details of the TPS design required to achieve equilibrium.

Many studies also focus exclusively on heating at the stagnation point. For hypersonic waveriders, the area around the stagnation region is relatively small, so while the heat flux is large, the total accumulation of energy due to the stagnation point heating might be less significant. This study will show that stagnation point heating is not always the most critical design consideration.

\section{Review of Heat Transfer and TPS Modeling}

The TPS modeling additions to MASIV can be split into three primary areas for analysis: 1) heat flux to the vehicle surface, 2) conduction through the passive thermal insulation layers, and 3) the heat exchanger model for active cooling. This section reviews the basic modeling techniques for each area.

\section{A. Heat Flux at Vehicle Surface}

Heat flux at the vehicle surface consists of convection from the surrounding air to the vehicle walls and radiation from the vehicle walls to the surrounding air.

\section{Convective Heat Flux}

A thin boundary layer is assumed for the purpose of calculating the convective heat flux. This assumption is appropriate for vehicles at low to moderate hypersonic Mach numbers. In order to calculate the convective heat flux $q_{\text {conv }}^{\prime \prime}$ at a point on the vehicle surface, a heat transfer coefficient $C_{h}$ is defined as:

$$
C_{h}=\frac{q_{\text {conv }}^{\prime \prime}}{\rho_{e} u_{e} c_{p}\left(T_{a w}-T_{w}\right)}
$$

where $\rho_{e}$ and $u_{e}$ are the density and velocity, respectively, outside the boundary layer, $c_{p}$ is the specific heat at constant pressure of the air, $T_{w}$ is the wall temperature, and $T_{a w}$ is the adiabatic wall temperature. The flow variables external to the boundary layer $\left(\rho_{e}, u_{e}, c_{p}\right)$ are obtained from current MASIV subroutines. The adiabatic wall temperature $T_{a w}$ is calculated using a recovery factor $r$ :

$$
r=\frac{T_{a w}-T_{e}}{T_{0 e}-T_{e}}
$$


where $T_{e}$ and $T_{0 e}$ are the static and total temperatures, respectively, external to the boundary layer. It can be seen from Eq. 5 that $T_{a w}$ is also a function of the flow variables external to the boundary layer. It is common to correlate the recovery factor to the flow Prandtl number $\operatorname{Pr}$; but as noted by White in Ref. 24, for compressible heat transfer with pressure gradients, recovery factor calculations based on CFD results are preferred to Prandtl number formulas. However, CFD is too expensive for the current reduced-order model. For the purpose of this study, the following correlations from Ref. 24, for the laminar and turbulent flow recovery factors when $\mathrm{Pr}$ is close to unity, are used:

$$
\begin{aligned}
r_{\text {lam }} & =\operatorname{Pr}^{1 / 2} \\
r_{\text {turb }} & =\operatorname{Pr}^{1 / 3}
\end{aligned}
$$

The heat transfer coefficient $C_{h}$ in Eq. 4 is related to the skin friction coefficient $C_{f}$ using an appropriate Reynolds analogy for compressible flow: ${ }^{24}$

$$
C_{h}=\frac{C_{f}}{2 \operatorname{Pr}^{2 / 3}}
$$

To solve for the heat flux $q_{\text {conv }}^{\prime \prime}$ in Eq. 4, the last step is to calculate the skin friction coefficient $C_{f}$. The reference temperature method is a popular method to find $C_{f}$ for laminar compressible flat plate boundary layers. ${ }^{24}$ The reference temperature method employs a modified version of the laminar flat plate formula:

$$
C_{f}=\frac{0.664 \sqrt{C R\left(T^{*}\right)}}{\sqrt{R e_{x}}}
$$

where $R e_{x}$ is the Reynolds number based on $x$ (the distance from the leading edge) and $C R$ is the ChapmanRubesin parameter evaluated at the Eckert reference temperature $T^{*}$ :

$$
\frac{T^{*}}{T_{e}}=0.5+0.039 M_{e}^{2}+0.5 \frac{T_{w}}{T_{e}}
$$

where $M_{e}$ is the Mach number external to the boundary layer. The Chapman-Rubesin parameter can be approximated as follows:

$$
C R\left(T^{*}\right)=\left(T^{*} / T_{e}\right)^{-1 / 3}
$$

The Van Driest II method is the most common and accurate method for solving turbulent compressible flat plate boundary layers and is discussed in Ref. 24. The reference temperature method and Van Driest II method both result in the following relationships for the convective heat flux (found by combining Eqs. 4 $10)$ :

$$
\begin{aligned}
& q_{\text {conv }}^{\prime \prime} \propto x^{-1 / 2} \\
& q_{\text {conv }}^{\prime \prime} \propto \rho_{e}^{1 / 2} \\
& q_{\text {conv }}^{\prime \prime} \propto u_{e}^{1 / 2} \\
& q_{\text {conv }}^{\prime \prime} \propto\left(T_{a w}-T_{w}\right) \approx\left(T_{0 e}-T_{w}\right)
\end{aligned}
$$

\section{Radiative Heat Flux}

For re-entry vehicles, at very high Mach numbers, the surrounding air reaches high enough temperature that radiation from the air particles to the vehicle surface must be considered for an accurate heat flux estimation. ${ }^{1}$ The current study, however, only considers flight up to approximately Mach 10, in which case, only the radiation cooling from the hot vehicle surface to the surrounding air is considered. Grey body radiation is assumed and the radiation heat flux $q_{\text {rad }}^{\prime \prime}$ is calculated at a point along the surface using the Stefan-Boltzmann law:

$$
q_{\mathrm{rad}}^{\prime \prime}=\varepsilon \sigma T_{w}^{4}
$$

where $\sigma$ is the Stefan-Boltzmann constant, $\varepsilon$ is the emissivity of the vehicle surface material, and $T_{w}$ is the wall temperature. 


\section{Balance Between Convection and Radiation}

The radiative heat flux is directly proportional to the wall temperature as seen in Eq. 12, where as, for fixed $T_{a w}$ and when $T_{a w}>T_{w}$, the convective heat flux is inversely proportional to $T_{w}$. A schematic of the boundary layer temperature profile is shown in Fig. 4 for two different wall temperatures when flow external to the boundary layer is fixed.

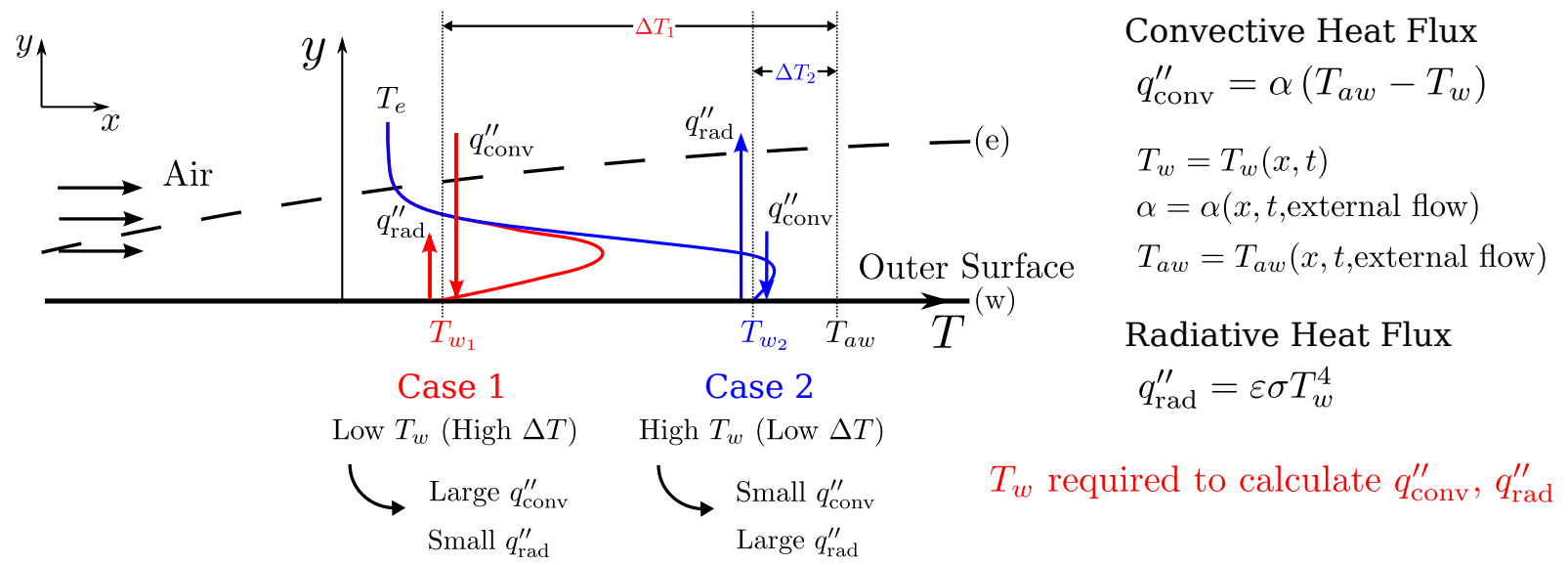

Figure 4. Boundary layer temperature profile for two different wall temperatures, $T_{w}$. The wall temperature is required to calculate both the convective and radiative heat flux. In the current study, $T_{w}$ results from solving $1 \mathrm{D}$ conduction through the wall. $\left(\alpha=C_{h} \rho_{e} u_{e} c_{p}.\right)$

The wall temperature is required to calculate both radiation and convection. In the current study, the wall temperature is obtained by solving one-dimensional conduction through the wall (with appropriate boundary conditions) as discussed in Part B of the current section. In a special case, however, when the convective heat flux equals the radiative heat flux (see Fig. 5), the wall temperature can be directly solved. This assumption is made in several studies but it will be shown in the current paper that the assumption is in general not valid.

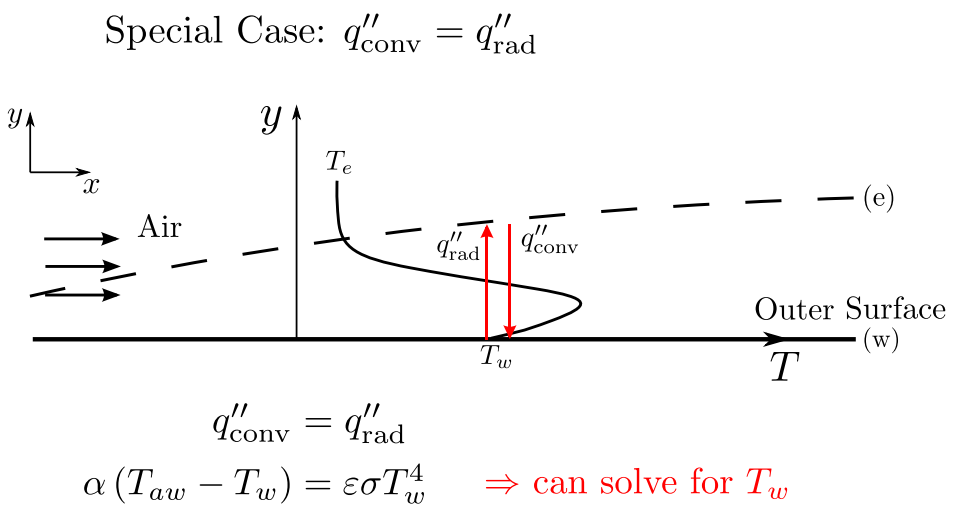

Figure 5. Boundary layer temperature profile for special case where the convective and radiative heat flux are equal. In this case, the wall temperature can be found without solving 1D conduction through the wall.

\section{Stagnation Point Heat Flux}

For hypersonic vehicles, the nose and leading edge stagnation points are regions of large heat flux and several recent studies involving hypersonic vehicle design have focused solely on the stagnation region. ${ }^{1,3}$ In Ref. 25, Tauber provides an expression of stagnation point heating for a swept, infinite cylinder: 


$$
q_{s, \mathrm{cyl}}^{\prime \prime} \approx 1.29 \times 10^{-4}\left(\frac{\rho_{\infty}}{r_{\mathrm{cyl}}}\right)^{0.5}\left(1-0.18 \sin ^{2} \Lambda\right) V_{\infty}^{3}\left(1-\frac{h_{w}}{h_{a w}}\right) \cos \Lambda
$$

where $q_{s, \text { cyl }}^{\prime \prime}$ is the heat flux at the cylinder stagnation point in $\mathrm{W} / \mathrm{m}^{2}, \rho_{\infty}\left[\mathrm{kg} / \mathrm{m}^{3}\right]$ and $V_{\infty}[\mathrm{m} / \mathrm{s}]$ are the free-stream density and velocity respectively, $r_{\text {cyl }}[\mathrm{m}]$ is the cylinder radius, and $\Lambda$ is the sweep angle. (Note that the relationship in Eq. 13 does not have consistent units.) The enthalpy at the wall $h_{w}[\mathrm{~J} / \mathrm{kg}]$ accounts for the wall temperature $T_{w}$ :

$$
h_{w}=c_{p} T_{w}
$$

and the adiabatic wall enthalpy $h_{a w}$ is approximated as:

$$
h_{a w} \approx h_{\infty}+0.5 V_{\infty}^{2}\left(1-0.18 \sin ^{2} \Lambda\right)
$$

where $h_{\infty}$ is the free-stream enthalpy. Note that as the wall temperature approaches the adiabatic wall temperature, the heat flux approaches zero. Also note that the stagnation point heat flux is inversely proportional to the radius.

Equation 13 is obtained by first solving the boundary layer equations with the stagnation point velocity gradient approximated by Newtonian impact theory. Therefore, inherent in Eq. 13 is the assumption that a thin boundary layer exists and that the flight Mach number is above approximately 4. Equation 13 is an engineering correlation found by curve fitting to the solved boundary layer equations. Tauber compares the results of Eq. 13 to experimental data and finds the data fits within a $\pm 25 \%$ spread. Similar forms for stagnation point heating are utilized in Refs. 3 and 1 and a similar form is also discussed further in Ref. 26.

\section{B. Conduction Through Passive Thermal Protection System}

Heat transfer through the insulating layers is modeled using the unsteady, one-dimensional heat conduction equation as discussed in Ref. 2:

$$
\rho c_{p} \frac{\partial T}{\partial t}=\frac{\partial}{\partial y}\left(k \frac{\partial T}{\partial y}\right)
$$

where $\rho, c_{p}$, and $k$ are the density, specific heat and thermal conductivity of the TPS material respectively. The temperature $T$ of the TPS material varies with time $t$ and also varies the direction normal to the surface $y$. The thickness of the insulation is small enough compared to its length that a one-dimensional assumption is appropriate. Also, conduction through the material is relatively slow and energy accumulates over time, hence the need to model the temperature as unsteady. The TPS is made of different materials sandwiched together, so the material properties will vary with location (i.e. $\rho=\rho(y), c_{p}=c_{p}(y), k=k(y)$ ).

Two boundary conditions and an initial condition are required to solve Eq. 16. A schematic of the temperature profile through the TPS at two different times is shown in Fig. 6. The Outer Surface (Station 1 in Fig. 6) is the surface exposed to the air (hence the temperature at Station $1, T_{1}$, is also the wall temperature $T_{w}$ used to solve for radiation and convection). The boundary condition applied at the Outer Surface is that the net heat flux into the surface $q_{\text {net }}^{\prime \prime}$ equals the conduction at the surface:

$$
\left(k \frac{\partial T}{\partial y}\right)_{y=y_{1}}=q_{\text {net }}^{\prime \prime}=q_{\mathrm{conv}}^{\prime \prime}-q_{\mathrm{rad}}^{\prime \prime}
$$

The conduction problem is coupled to the calculation of heat flux at the vehicle surface since the wall temperature is required to compute $q_{\mathrm{conv}}^{\prime \prime}$ and $q_{\mathrm{rad}}^{\prime \prime}$. The Inner Surface (Station 4 in Fig. 6) is the boundary between the TPS and vehicle interior. For the boundary condition, the Inner Surface is assumed perfectly insulated:

$$
\left.\frac{\partial T}{\partial y}\right|_{y=y_{4}}=0
$$

The assumption of perfect insulation at Station 4 is appropriate because the vehicle interior is comprised mostly of the fuel tank, which has a much lower thermal conductivity than the structural material in the inner most layer of the TPS.

The first layer of the TPS (see Fig. 6) serves both as a radiation shield and to protect the insulation material. The radiation shield is usually made of a highly conductive material such as steel honeycomb 
and quickly absorbs energy and increases in temperature (the higher surface temperature results in larger radiative cooling according to Eq. 12). The insulating layer has a very low thermal conductivity to slow the transfer of energy to the last layer of the TPS, the titanium skin.

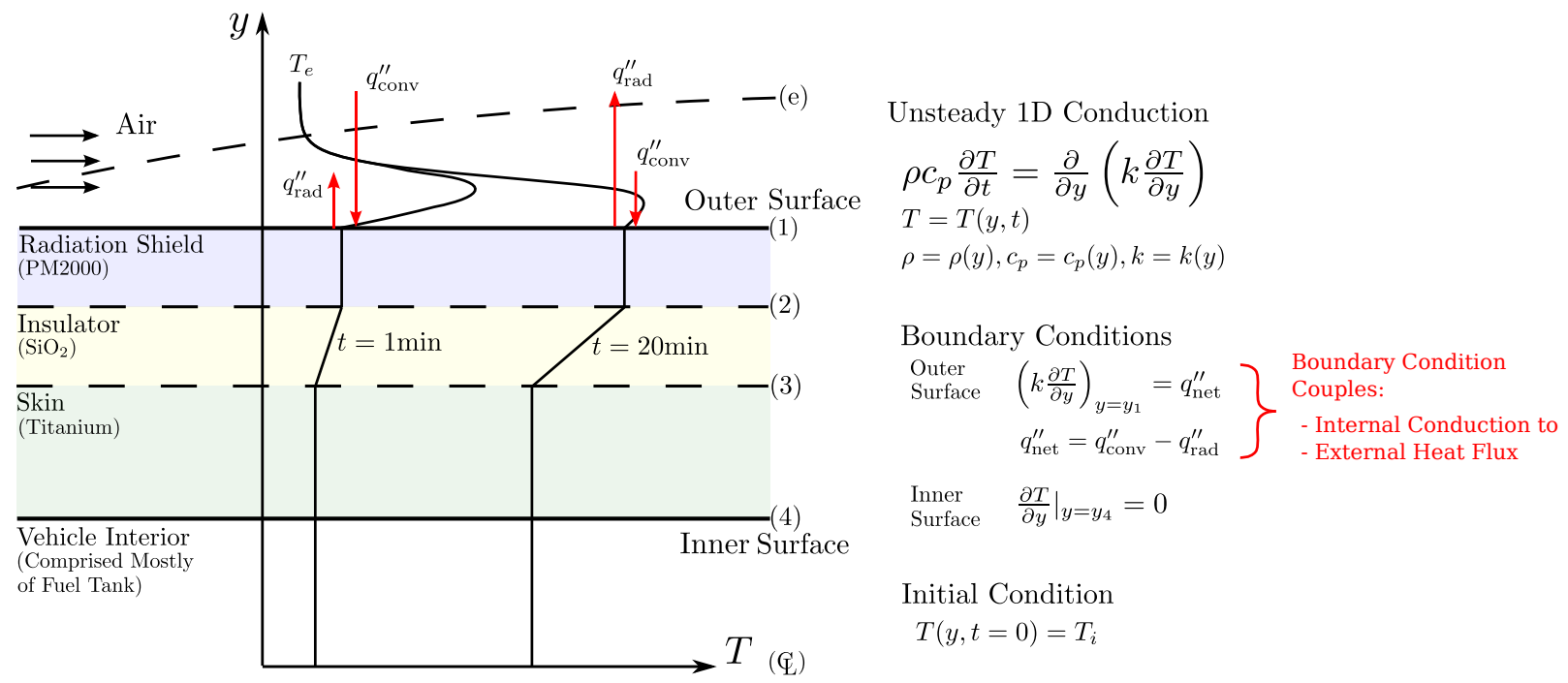

Figure 6. Schematic of temperature profiles within the passive TPS at times $t=1 \mathrm{~min}$ and $t=20 \mathrm{~min}$. The inner surface is assumed perfectly insulated. The net heat flux at the outer surface is required to solve the unsteady 1D conduction problem, coupling the internal conduction to the external heat flux.

The boundary conditions shown in Fig. 6 are for the passive TPS only. In the case of active cooling, conduction also occurs, but the boundary condition at the Inner Surface is no longer insulated. Figure 7 shows a schematic of the temperature profile in the TPS at two times when active cooling is employed. The boundary condition at the Outer Surface (Station 1 in Fig. 7) is exposed to the air and remains the same as in Fig. 6. The Inner Surface (Station 2 in Fig. 7) however, is exposed to a heat exchanger which generates a heat flux $q_{\text {HEX }}^{\prime \prime}$ that transfers heat energy from the TPS to the liquid hydrogen fuel. The boundary condition at the Inner Surface is that the heat flux $q_{\mathrm{HEX}}^{\prime \prime}$ matches the conduction at Station 2:

$$
\left(k \frac{\partial T}{\partial y}\right)_{y=y_{2}}=q_{H E X}^{\prime \prime}
$$

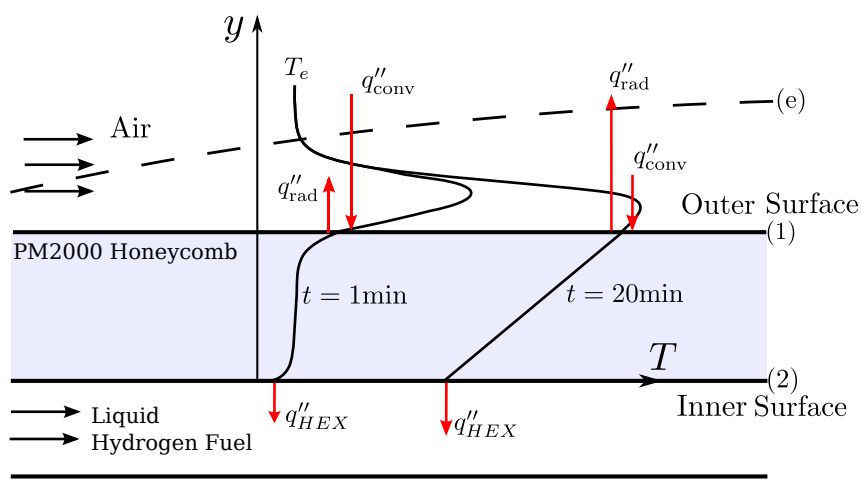

Unsteady 1D Conduction

$$
\begin{aligned}
& \rho c_{p} \frac{\partial T}{\partial t}=\frac{\partial}{\partial y}\left(k \frac{\partial T}{\partial y}\right) \\
& T=T(y, t)
\end{aligned}
$$

$\left.\begin{array}{ll}\begin{array}{l}\text { Boundary Conditions } \\ \text { Outer }\end{array} & \left(k \frac{\partial T}{\partial y}\right)_{y=y_{1}}=q_{\text {net }}^{\prime \prime} \\ \text { Surface } & \\ & q_{\text {net }}^{\prime \prime}=q_{\text {conv }}^{\prime \prime}-q_{\text {rad }}^{\prime \prime} \\ \text { Inner } & \left(k \frac{\partial T}{\partial y}\right)_{y=y_{2}}=q_{\mathrm{HEX}}^{\prime \prime}\end{array}\right\} \begin{aligned} & \text { Boundary Condition } \\ & \text { Couples: } \\ & - \text { Internal Conduction to } \\ & - \text { External Heat Flux and } \\ & - \text { Cooling Channel Heat Flux }\end{aligned}$

Initial Condition

$T(y, t=0)=T_{i}$

Figure 7. Schematic of two temperature profiles within the TPS wall when a heat exchanger is employed for active cooling. The unsteady 1D conduction problem is coupled to both the external heat flux problem (at the outer surface) and the cooling channel heat flux calculation (at the Inner Surface). 


\section{Heat Exchanger for Active Cooling System}

An active cooling system is employed for the most critical regions, where high heating occurs. The heat exchanger model in the current study utilizes the liquid hydrogen fuel at super-critical conditions, similar to the nozzle cooling channels used in rocket engines as discussed by Huzel and Huang in Ref. 13. A schematic of the heat exchanger is shown in Fig. 8. The fuel flow is modeled as a one-dimensional flow and the temperature of the fuel $T_{F}$ varies along the axial direction $x$. The temperature at the cooling channel wall $\left(T_{w c}\right.$ in Fig. 8) also varies along the axial direction. The temperature difference $\left(T_{w c}-T_{F}\right)$ results in a convective heat flux $q_{\mathrm{HEX}}^{\prime \prime}$ from the wall to the heat exchanger fluid:

$$
q_{\mathrm{HEX}}^{\prime \prime}=h_{c}\left(T_{w c}-T_{F}\right)
$$

where $h_{c}$ is the convective heat transfer coefficient. The heat transfer coefficient $h_{c}$ is a function of the coolant flow properties and is provided in Ref. 13 for supercritical hydrogen:

$$
h_{c}=\frac{0.029 c_{p} \mu^{0.2}}{\operatorname{Pr}^{2 / 3}}\left(\frac{\dot{m}}{A}\right)^{0.8}\left(\frac{1}{D_{c}^{0.2}}\right)\left(\frac{T_{F}}{T_{w c}}\right)^{0.55}
$$

where $A$ and $D_{c}$ are the cross-sectional area and hydraulic diameter, respectively, of the cooling channel and $\dot{m}$ is the coolant mass flow rate. The Prandtl number, $c_{p}$, and $\mu$ are functions of the coolant temperature and pressure. The properties $\operatorname{Pr}, c_{p}$, and $\mu$ for supercritical liquid hydrogen can vary greatly with temperature and the variation is accounted for by using the data compiled in Ref. 27.

As energy is transfered from the wall to the fuel, the fuel temperature will rise according to the steady, one-dimensional energy equation:

$$
\dot{m} c_{p} \frac{d T_{F}}{d x}=P q_{\mathrm{HEX}}^{\prime \prime}
$$

where $P$ is the cooling channel perimeter. Equation 22 neglects the change in kinetic energy through the cooling channel. This assumption is justified because the heat flow is much larger than the kinetic energy. The pressure change is also neglected in Eq. 22, allowing for the energy equation and the momentum equation to be decoupled. After the fuel temperature through the cooling channel is solved, the momentum equation can be used separately to estimate the pressure drop.

To solve Eq. 22, $T_{F}$ at the boundary $x=0$ is set to the fuel tank temperature. The heat flux $q_{\mathrm{HEX}}^{\prime \prime}$ varies with time as the coolant channel wall temperature $T_{w c}$ changes, making the solution to Eq. 22 a quasi-unsteady process requiring an initial condition. At the initial time $t=0, T_{w c}$ is set uniformly to the initial wall temperature $T_{i}$ and the fuel temperature $T_{F}$ is set uniformly to the initial fuel tank temperature. A schematic of the $T_{w c}$ and $T_{F}$ variation in $x$ is shown in Fig. 8 for two different times.

\section{Results and Discussion}

This section presents results for the individual subsystems added to MASIV, including results for: heat flux to the vehicle surface, the passive thermal protection system, and the active thermal protection system. In addition, physical insights and engineering trade-offs gleaned from the models are discussed.

\section{A. Heat Flux to Vehicle Surface}

The results presented here include convective heat flux to the vehicle internal and external surfaces, and heat flux at the vehicle stagnation point

\section{Convection to Vehicle External Surface}

The vehicle external surface is discretized into multiple triangular panels as shown in Fig. 1. The flow over each panel is calculated independent of the surrounding panels and based on the panel's local orientation to the free-stream. As discussed by Bowcutt in Ref. 28, this method of modeling the external flow is appropriate for waverider-type vehicles at hypersonic speeds. The external flow is calculated using a compressible, inviscid flow assumption. Pressure gradients on the external surface are neglected and the boundary layer thickness is assumed small enough to not effect the flow external to the boundary layer. The heat flux on the external surface is calculated using the methods discussed in Part A of Section IV. Figure 9 shows the convective 

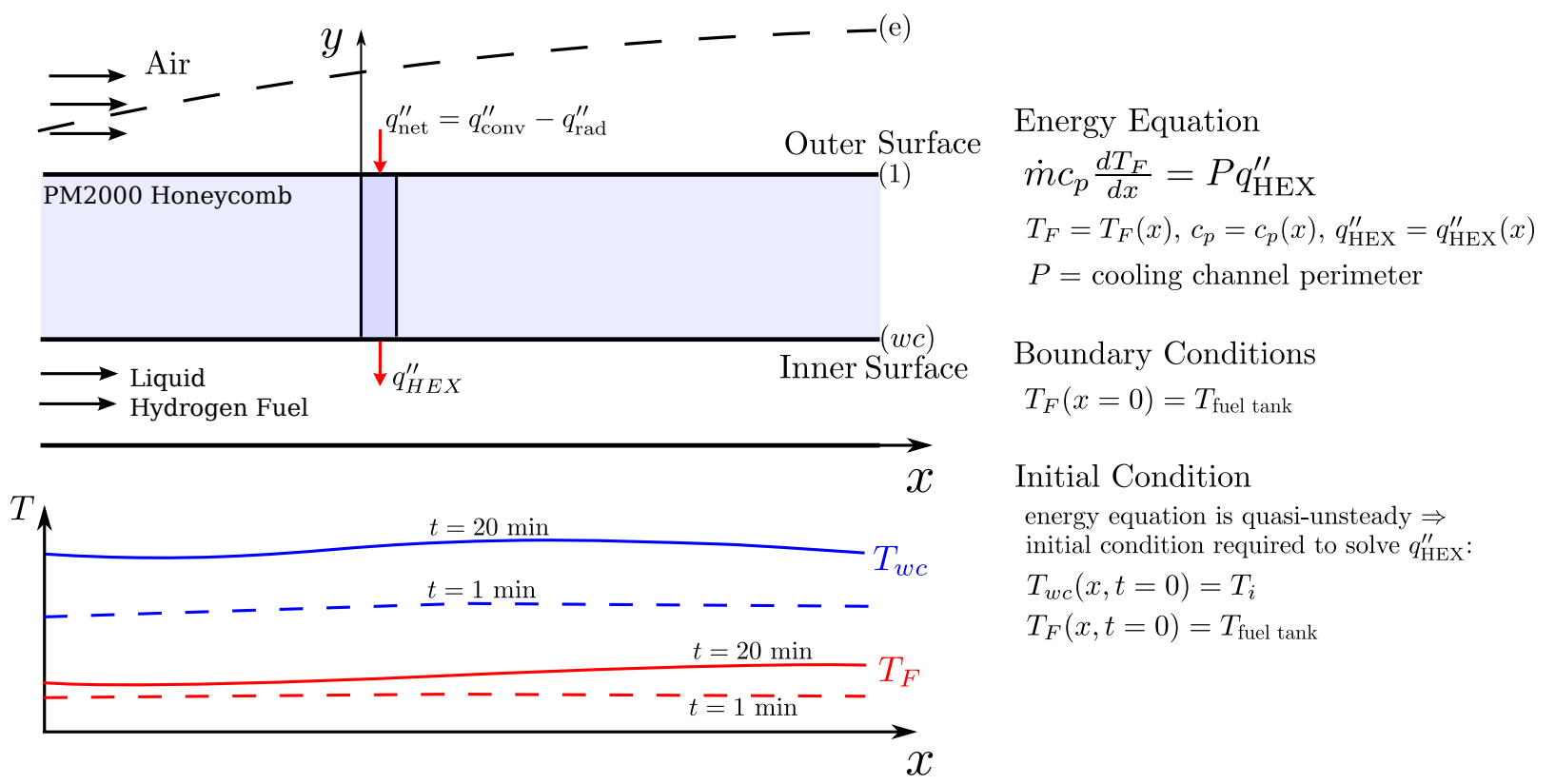

Initial Condition

energy equation is quasi-unsteady $\Rightarrow$ initial condition required to solve $q_{\mathrm{HEX}}^{\prime \prime}$ :

$T_{w c}(x, t=0)=T_{i}$

$T_{F}(x, t=0)=T_{\text {fuel tank }}$

Figure 8. Schematic of cooling channel temperature profile. Figure also shows heat exchanger governing equations and boundary conditions. The temperature at the inner surface is required to solve for $q_{\mathrm{HEX}}^{\prime \prime}$, coupling the heat exchanger calculation to the 1D conduction problem.

heat flux on the top and bottom surfaces of the MAX-1 vehicle. The vehicle is trimmed at a free-stream dynamic pressure of $q_{\infty}=50 \mathrm{kPa}$ and a Mach number of $M_{\infty}=10$. The results shown in Fig. 9 are for a uniform wall temperature of $T_{w}=300 \mathrm{~K}$ (at a uniform wall temperature, the radiative heat flux is also uniform according to Eq. 12, and hence results for radiation are not shown). Note that the heat flux is highest at the vehicle leading edges (this is expected because $q_{c o n v}^{\prime \prime} \propto x^{-1 / 2}$ as discussed earlier) and the inlet ramp. (Most of the inlet ramp is not shown in Fig. 9 as the inlet ramp is part of the interal heat flux calculation.)

\section{Convection to Propulsion System Flow-path and Stagnation Point Heating}

The convective heat flux along the propulsion system flow-path is shown in Fig. 10 for two free-stream dynamic pressures: $q_{\infty}=50 \mathrm{kPa}$ and $q_{\infty}=100 \mathrm{kPa}$. In both cases, the vehicle is trimmed at a flight Mach number of $M_{\infty}=10$ and a uniform wall temperature specified at $T_{w}=300 \mathrm{~K}$. The propulsion system flow-path consists of the inlet, followed by the isolator, combustor, and finally the nozzle.

Also shown in Fig. 10 is the stagnation point heat flux. To obtain the heat flux at the leading edge of the MAX-1 vehicle, the sweep angle is set to zero in Eq. 13:

$$
q_{L E}^{\prime \prime}=1.29 \times 10^{-4}\left(\frac{\rho_{\infty}}{r_{L E}}\right)^{0.5} V_{\infty}^{3}\left(1-\frac{h_{w}}{h_{a w}}\right)
$$

where $r_{L E}$ is the leading edge radius. Ohlhorst estimates the leading edge radius for the $\mathrm{X}-43$ to be 0.03 $\mathrm{m} .{ }^{29}$ Due to the similarities between the X-43 and MAX-1 vehicles, $r_{L E}$ is also set to $0.03 \mathrm{~m}$ for the MAX-1. At the free-stream dynamic pressures of $q_{\infty}=50 \mathrm{kPa}$ and $q_{\infty}=100 \mathrm{kPa}$, the resulting stagnation point heat fluxes are $q_{L E}^{\prime \prime}=2.1 \times 10^{6} \mathrm{~W} / \mathrm{m}^{2}$ and $q_{L E}^{\prime \prime}=2.8 \times 10^{6} \mathrm{~W} / \mathrm{m}^{2}$ respectively.

The results in Fig. 10 show that, while the stagnation point heating is large compared to heating along the rest of the inlet, the magnitude is comparable to heating in the isolator and combustor. However, the surface area at the stagnation point is small compared to the isolator and combustor, indicating that the isolator and combustor are the most critical regions to thermal management. Figure 10 also shows that at higher free-stream dynamic pressure (i.e. lower altitude and hence higher free-stream density), the convective heating is larger in general. At the two conditions shown in Fig. 10, the free-stream temperatures are close 

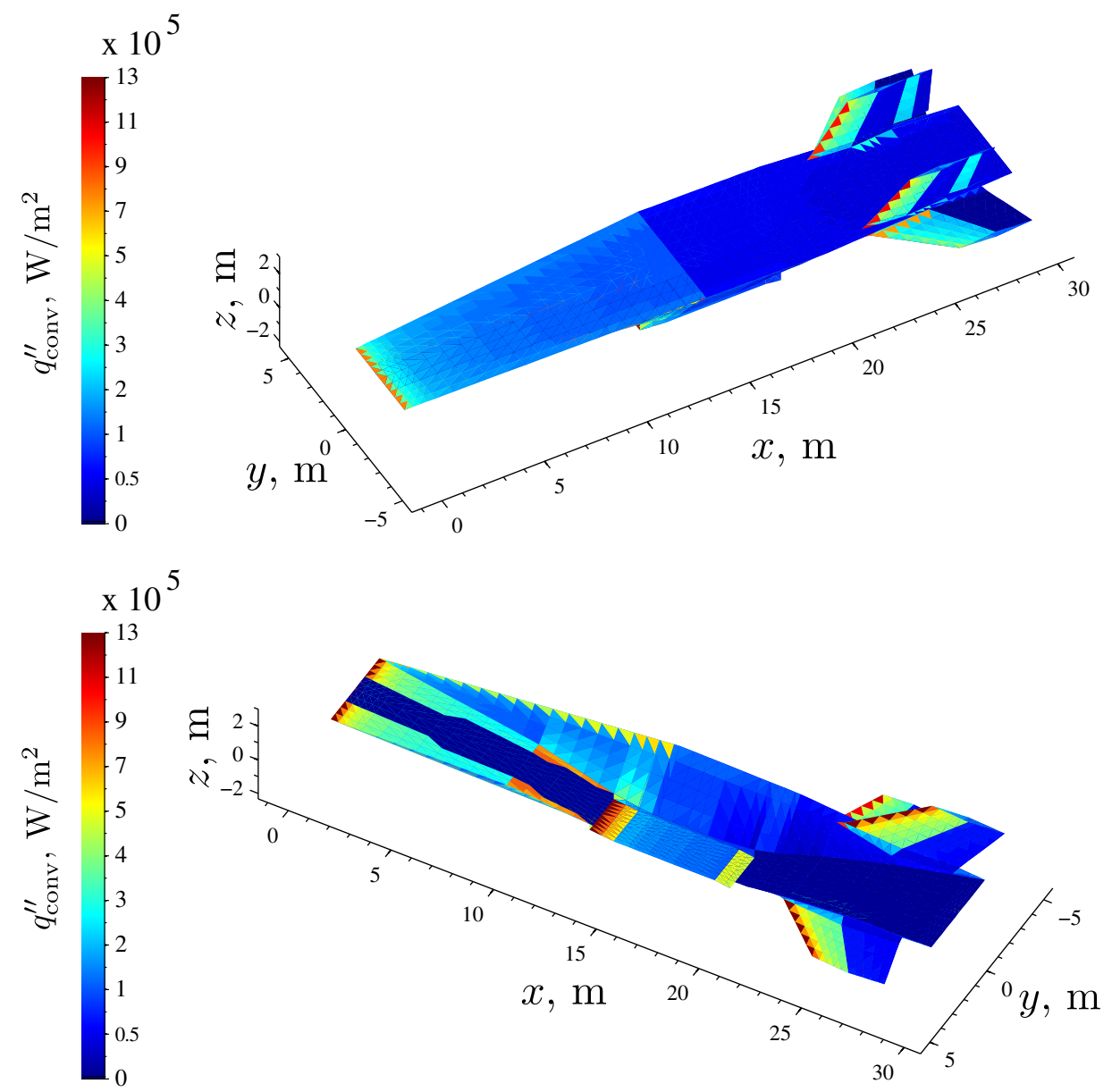

Figure 9. Convective heat flux $q_{\mathrm{conv}}^{\prime \prime}$ on external surface of MAX-1. The vehicle is trimmed at flight conditions of $M_{\infty}=10$ and $q_{\infty}=50 \mathrm{kPa}$. The surface temperature is specified to be a uniform value of $T_{w}=300 \mathrm{~K}$.

$\left(T_{\infty}=225 \mathrm{~K}\right.$ at $M_{\infty}=10, q_{\infty}=50 \mathrm{kPa}$ versus $T_{\infty}=232 \mathrm{~K}$ at $\left.M_{\infty}=10, q_{\infty}=100 \mathrm{kPa}\right)$ and hence the free-stream velocities are also similar. The free-stream density however, varies drastically $\left(\rho_{\infty}=0.0107 \mathrm{~K}\right.$ at $M_{\infty}=10, q_{\infty}=50 \mathrm{kPa}$ versus $\rho_{\infty}=0.0221 \mathrm{~K}$ at $\left.M_{\infty}=10, q_{\infty}=100 \mathrm{kPa}\right)$ and because $q_{\text {conv }}^{\prime \prime} \propto \rho_{e}^{1 / 2}$ as shown in Eq. 11b, the larger convective heating at $q_{\infty}=100 \mathrm{kPa}$ is expected. Also, after the leading edge, the flow is initially laminar and transitions to turbulent at the specified transition Reynolds number of $10^{7}$; note that at higher free-stream dynamic pressure, the transition to turbulent occurs earlier. As the flow along the inlet is processed by oblique shocks, the density rises along with the convective heat flux.

Also, the convection along the propulsion system flow-path shown in Fig. 10 for $q_{\infty}=50 \mathrm{kPa}$ is at the same flight conditions as the results presented in Fig. 9 for convection on the external surface. Comparing the heat flux values in both figures, the heat flux at the leading edge and through the isolator and combusor is an order of magnitude larger than the remaining vehicle, indicating that these regions are more likely to require active cooling.

\section{B. Passive Thermal Protection System}

This section discusses the passive thermal protection system model added to MASIV. The passive thermal protection system is separated into the three regions shown in Fig. 2. The first two regions (the external surface and the propulsion system flow-path) are similar and are discussed together, followed by a discussion of the third region, the vehicle nose. 


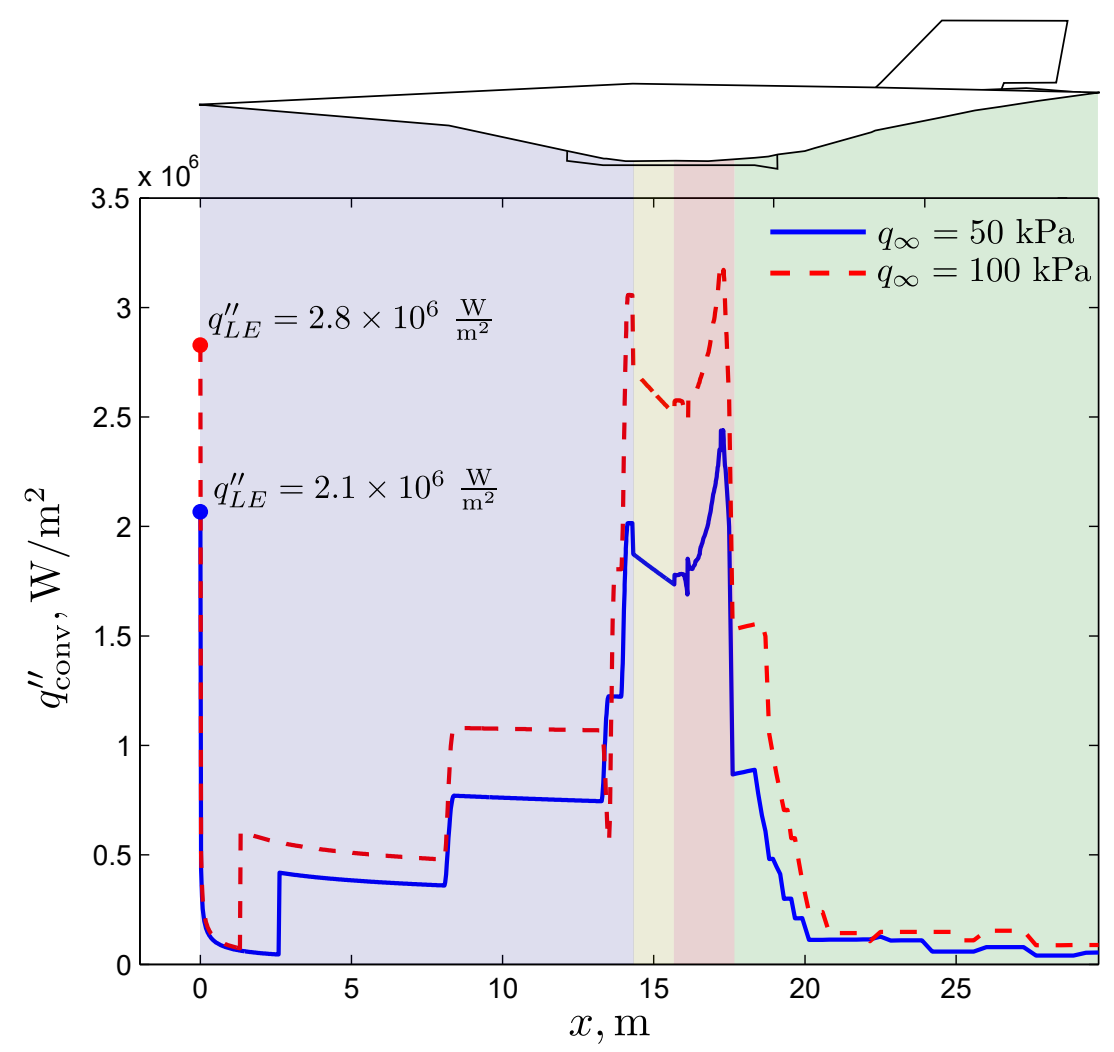

Figure 10. Convective heat flux $q_{\mathrm{conv}}^{\prime \prime}$ along the MAX-1 vehicle propulsion system flow-path for two free-stream dynamic pressures: $q_{\infty}=50 \mathrm{kPa}$ and $q_{\infty}=100 \mathrm{kPa}$. In both cases, the vehicle is trimmed at a flight Mach number of $M_{\infty}=10$ with a uniform wall temperature of $T_{w}=300 \mathrm{~K}$ specified. The stagnation point heat flux at the leading edge $q_{L E}^{\prime \prime}$ is also shown.

\section{External Surface and Propulsion System Flow-path}

The propulsion system flow-path consists of the compression inlet, the isolator, the combustor, and finally the nozzle. What distinguishes the propulsion system flow-path from the external surface is the intensity of the heat flux (the heat flux to the external surface is roughly an order of magnitude smaller, as shown in Part A of the current section). The passive TPS consists of three layers sandwiched together as shown in Fig. 11. The first layer, the radiation shield, is exposed to the air and experiences a convective and radiative heat flux. The insulation layer separates the radiation shield from the titanium skin and the skin is assumed perfectly insulated on the inner surface as discussed in Part B of Section IV.

Representative values for each TPS layer thickness are shown in Table 2 along with the thermal conductivity of each layer. Figure 12 shows the temperature distribution through the TPS layers along the propulsion system flow-path. The TPS layer thicknesses in Fig. 12 are the same values listed in Table 2 and are uniform along the axial direction. The vehicle is trimmed at the flight conditions of $M_{\infty}=10$ and $q_{\infty}=100 \mathrm{kPa}$. The results shown in Fig. 12 are after 40 minuets at the same free-stream conditions and both the convective heat flux and radiative cooling are accounted for. The results show that the temperatures are largest in the radiation shield, particularly through the isolator and combustor regions. (Note that active cooling in not employed in these results.) A large temperature gradient occurs in the insulation layer and the lowest temperatures occur in the titanium skin.

For comparison, Fig. 13 shows the temperature through the same TPS layer thickness as Fig. 12 except the flight Mach number is reduced to $M_{\infty}=7$ and the free-stream dynamic pressure is reduced to $q_{\infty}=50$ $\mathrm{kPa}$. While the isolator and combustor remain the most critical regions, the results indicate that for a given passive TPS design, the material temperatures can be reduced by flying within a designated safe flight envelope. 


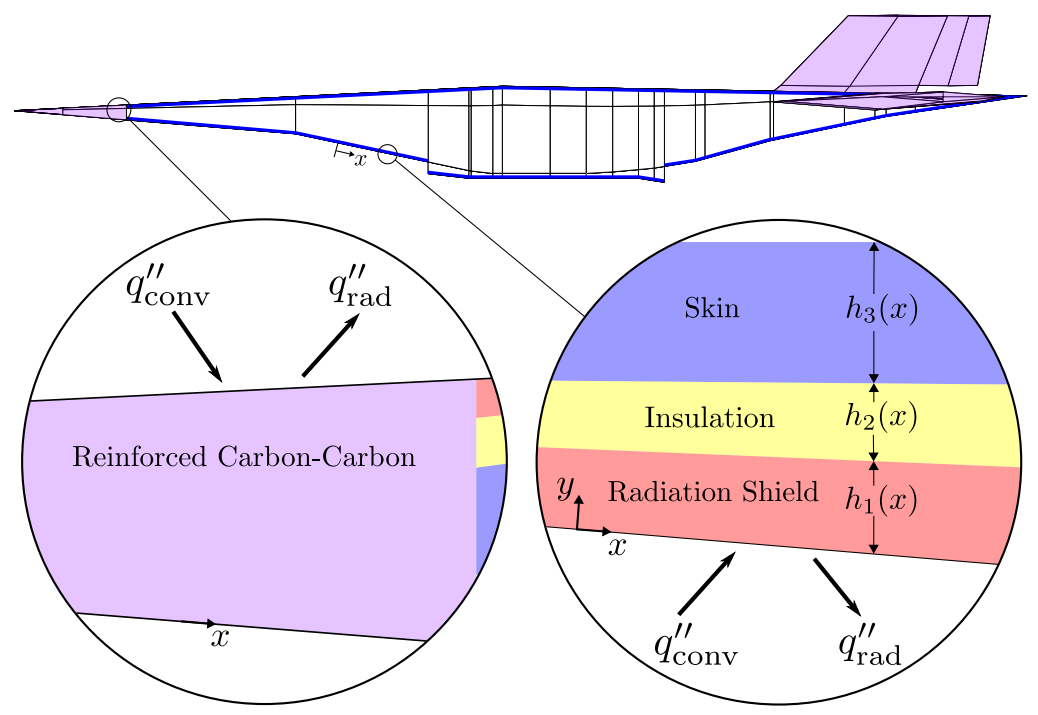

Figure 11. Schematic showing the individual material layers within the passive TPS.

Table 2. Passive thermal protection system layers for results shown in Figs. 12, 13, 14

\begin{tabular}{cccc}
\hline \hline Layer & Material & $\begin{array}{c}\text { Thickness, } \\
\mathrm{cm}\end{array}$ & $\begin{array}{c}\text { Conductivity, } \\
\mathrm{W} /(\mathrm{m} \cdot \mathrm{K})\end{array}$ \\
\hline 1 & $\mathrm{PM}^{2000 \text { Honeycomb }}$ & 6 & 27.7 \\
2 & $\mathrm{SiO}_{2}$ Insulation & 2.5 & 0.033 \\
3 & Titanium & 12 & 18 \\
\hline
\end{tabular}

Conduction through the passive TPS is modeled as unsteady because the heat energy accumulates within the material over time. The temperature contours shown in Figs. 12 and 13 are after 40 minuets of cruise. To see how the temperature changes with time, the unsteady temperature profiles are plotted along the propulsion system flow-path as shown in Fig. 14. The vehicle is trimmed at the flight conditions of $M_{\infty}=10$ and $q_{\infty}=100 \mathrm{kPa}$ and the TPS thicknesses are the same as those listed in Table. 2. The temperature profiles are shown at three location in: 1) the combustor (the most critical region), 2) the nozzle (the least critical region), and 3) the inlet. Note that besides the convective heat flux, the radiative cooling is also included at the outer surface. Figure 14 indicates that the temperature in the outer layer, the radiation shield, increases rapidly at first but then the rate of increase drops rapidly. This result is expected because as the temperature at the outer surface $T_{w}$ increases, the radiative cooling increases rapidly $\left(q_{\mathrm{rad}}^{\prime \prime} \propto T_{w}^{4}\right)$, and as $q_{\mathrm{rad}}^{\prime \prime}$ increases, the net heat flux into the surface decreases. Figure 14 indicates that the temperature within the titanium skin on the other hand, steadily increases during the cruise.

The results shown in Figs. 12 - 14 are at constant wall thicknesses (the same values listed in Table 2). To understand the effects of wall thickness on the material temperature, the thicknesses of both the radiation shield and the titanium skin are varied. Figure 15 a) shows how the maximum temperature within the titanium skin $T_{\max , T i}$ varies with skin thickness $h_{\mathrm{Ti}}$. The analysis is performed at a free-steam Mach number of 10 and a free-stream dynamic pressure of $50 \mathrm{kPa}$ and the results are presented at a location along the inlet at $x=10 \mathrm{~m}$. As $h_{\max }$ is varied, the thickness of the other layers remains fixed. Note the rapid decrease in $T_{\max , T i}$ as the skin thickness increases. These results are expected; the skin acts as a heat sink and as the thickness increases, there is more material to absorb the heat energy, reducing the overall temperature.

Figure $15 \mathrm{~b}$ ) shows how the wall temperature $T_{w}$ (the maximum temperature within the radiation shield) varies with the radiation shield thickness $h_{\mathrm{RS}}$. Unlike the titanium skin, increasing the thickness of the radiation shield has very little effect on the maximum temperature within the radiation shield. Only by increasing $h_{\mathrm{RS}}$ to an impractical thickness is any reduction in wall temperature after 40 minuets observed. The reason for the small variation in $T_{w}$ is demonstrated in Fig. 16. Figure 16 a) shows the convective 


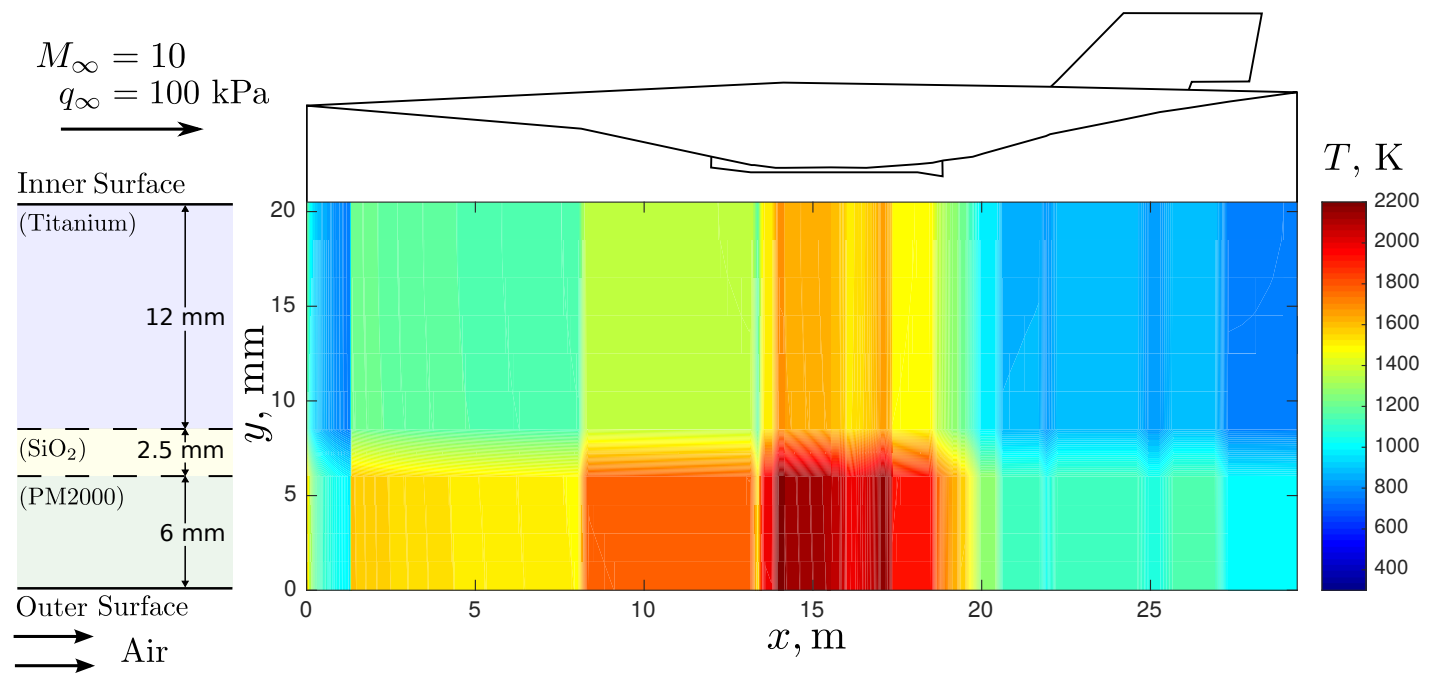

Figure 12. Temperature distribution inside passive TPS along the propulstion system flow-path. The vehicle is trimmed at $M_{\infty}=10$ and $q_{\infty}=100 \mathrm{kPa}$ and the results shown are after 40 minuets at the same trimmed flight condition.

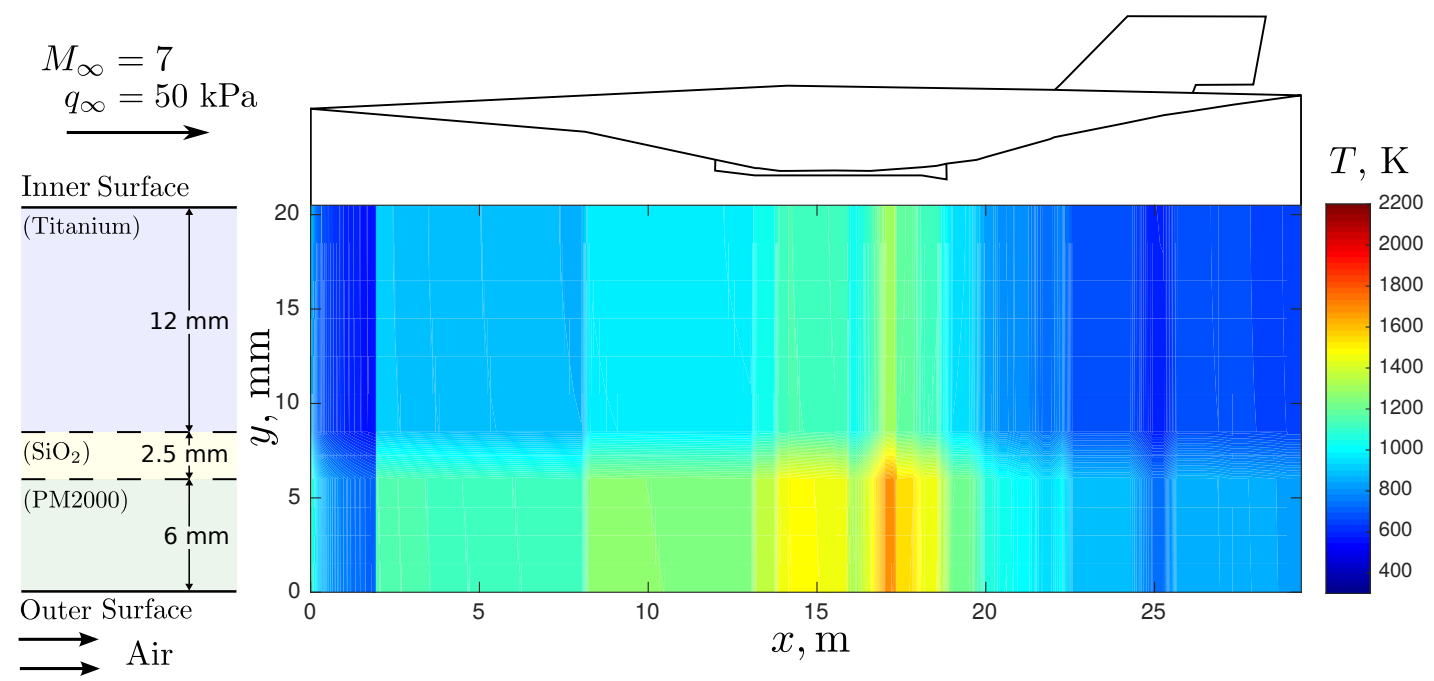

Figure 13. Temperature distribution inside passive TPS along the propulsion system flow-path. The vehicle is trimmed at $M_{\infty}=7$ and $q_{\infty}=50 \mathrm{kPa}$ and the results shown are after 40 minuets at the same trimmed flight condition. 


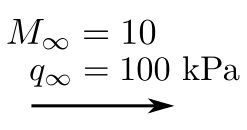

Inner Surface

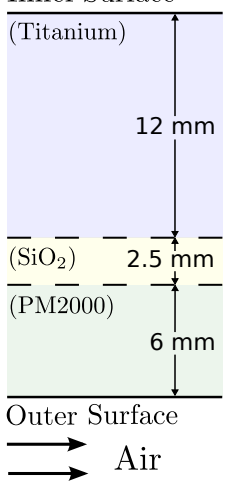

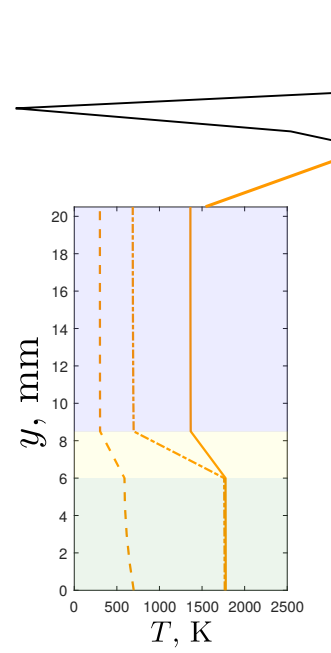

$T, \mathrm{~K}$

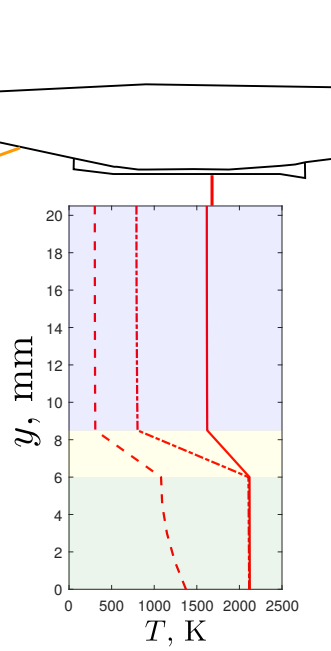

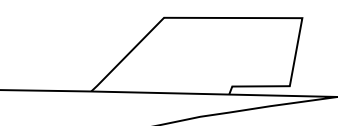
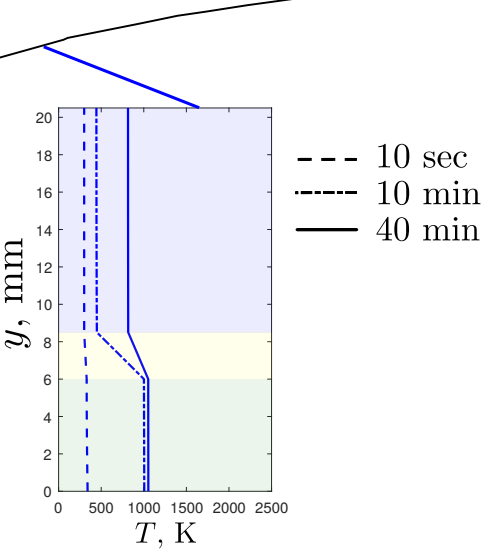

Figure 14. Temperature distribution inside passive TPS along the propulsion system flow-path. The vehicle is trimmed at $M_{\infty}=7$ and $q_{\infty}=50 \mathrm{kPa}$ and the results shown are after 40 minuets at the same trimmed flight condition.

and radiative heat flux at the vehicle surface for three values of $h_{\mathrm{RS}}$. As the radiation shield thickness increases, the tendency is for the wall temperature to decease (the radiation shield acts as a heat sink similar to the titanium skin). However, as the wall temperature decreases, the convective heat flux increases $\left(q_{\text {conv }}^{\prime \prime} \propto\left(T_{a w}-T_{w}\right)\right)$ while the radiative heat flux simultaneously decreases $\left(q_{\text {rad }}^{\prime \prime} \propto T_{w}^{4}\right)$. The result, as shown in Fig. $16 \mathrm{~b}$ ), is an increase in the net heat flux into the surface as $h_{R S}$ increases, negating any potential decrease in temperature within the radiation shield.

The convective heat flux along the propulsion system flow-path shown in Fig. 10 is for a constant wall temperature of $300 \mathrm{~K}$. However, as the passive TPS absorbs during cruise, the wall temperature increase. The wall temperature $T_{w}$ and convective heat flux $q_{w}$ along the propulsive flow-path for two cruise conditions are shown in Fig. 17. The cruise conditions analyzed are: $M_{\infty}=10, q_{\infty}=100 \mathrm{kPa}$ and $M_{\infty}=7, q_{\infty}=50 \mathrm{kPa}$ and the results shown are after 40 minuets of cruise. The results again shows less severe heating at lower free-stream Mach numbers and dynamic pressures.

\section{Vehicle Nose Region}

Heating of the leading edge nose region is treated separately from heating of the remaining vehicle surface. Rather than modeling one-dimensional conduction through the surface, the nose is treated as a uniform mass of reinforced carbon-carbon. The approximation of a uniform mass is based on the thin profile of the nose as shown in Fig. 11. The contributions to the nose heating, $\dot{Q}_{\text {nose }}$, include the stagnation point heat flux at the leading edge and the convective flux through the top and bottom surfaces, along with radiative cooling based on the nose temperature. The nose temperature increases over time based on energy conservation:

$$
\frac{d E_{\text {nose }}}{d t}=\dot{Q}_{\text {nose }}
$$

where the nose energy $E_{\text {nose }}$ is calculated based on the nose temperature $T_{\text {nose }}$ as follows:

$$
E_{\text {nose }}=m c_{p} T_{\text {nose }}
$$

The mass $m$ and specific heat $c_{p}$ in the above equation are calculated for the reinforced carbon-carbon: $\rho=1790 \mathrm{~kg} / \mathrm{m}^{3}, c_{p}=1600 \mathrm{~J} /(\mathrm{kg} \cdot \mathrm{K}){ }^{30} \quad$ Figure 18 shows the stagnation point heat flux $q_{s, \mathrm{LE}}^{\prime \prime}$ and the radiative heat flux at the leading edge $q_{\text {rad,LE }}^{\prime \prime}$ over time for two cruise conditions: $M_{\infty}=10, q_{\infty}=100 \mathrm{kPa}$ and $M_{\infty}=7, q_{\infty}=50 \mathrm{kPa}$. Figure 19 show $T_{\text {nose }}$ versus time at the same cruise conditions. 

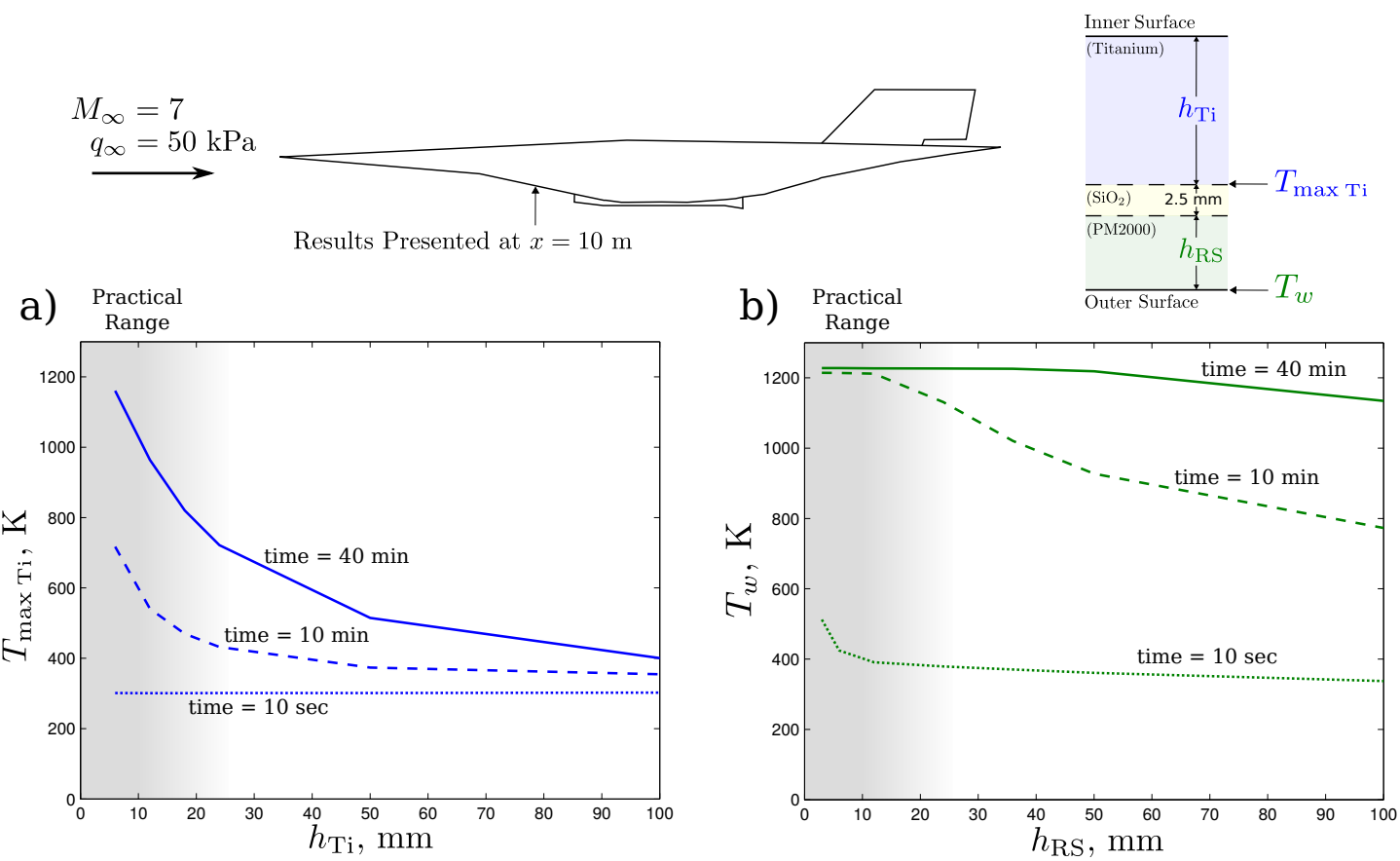

Figure 15. TPS temperature versus TPS thickness at a location along the inlet (10 meters from leading edge) for vehicle trimmed at $M_{\infty}=7$ and $q_{\infty}=50 \mathrm{kPa}$. a) Maximum temperature within the titanium skin $T_{\max }$ versus titanium thickness $\left.h_{\mathrm{Ti}}, \mathbf{b}\right)$ wall temperature $T_{w}$ versus radiation shield thickness $h_{\mathrm{RS}}$.
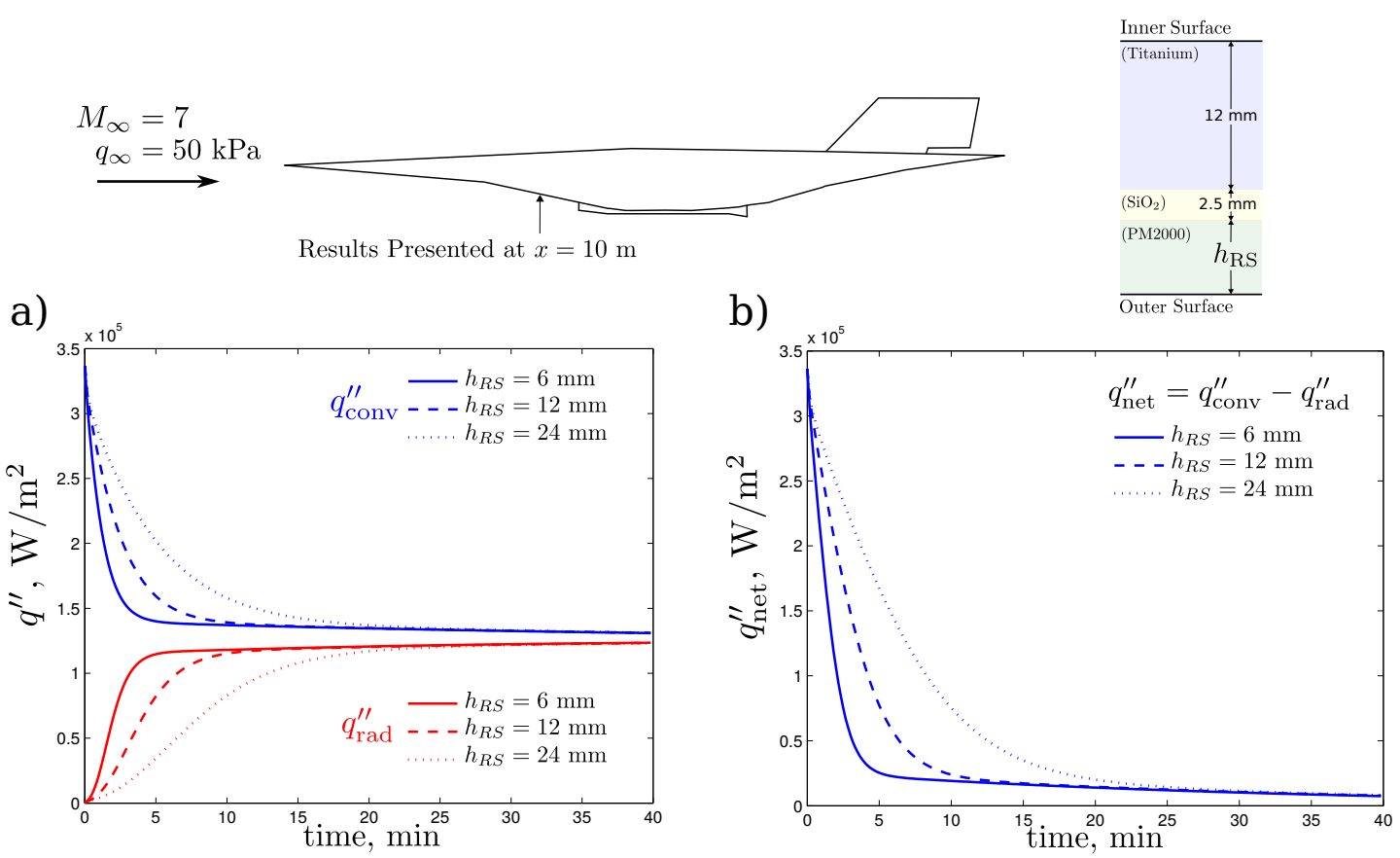

Figure 16. Heat flux versus time at a location along the inlet (10 meters from leading edge) for three values of radiation shield thickness $h_{\mathrm{RS}}$. The vehicle is trimmed at $M_{\infty}=7$ and $q_{\infty}=50 \mathrm{kPa}$. a) Convective heat flux $q_{\mathrm{conv}}^{\prime \prime}$ and radiative heat flux $q_{\mathrm{rad}}^{\prime \prime}$ versus time, b) net heat flux $q_{\text {net }}^{\prime \prime}$ versus time. 

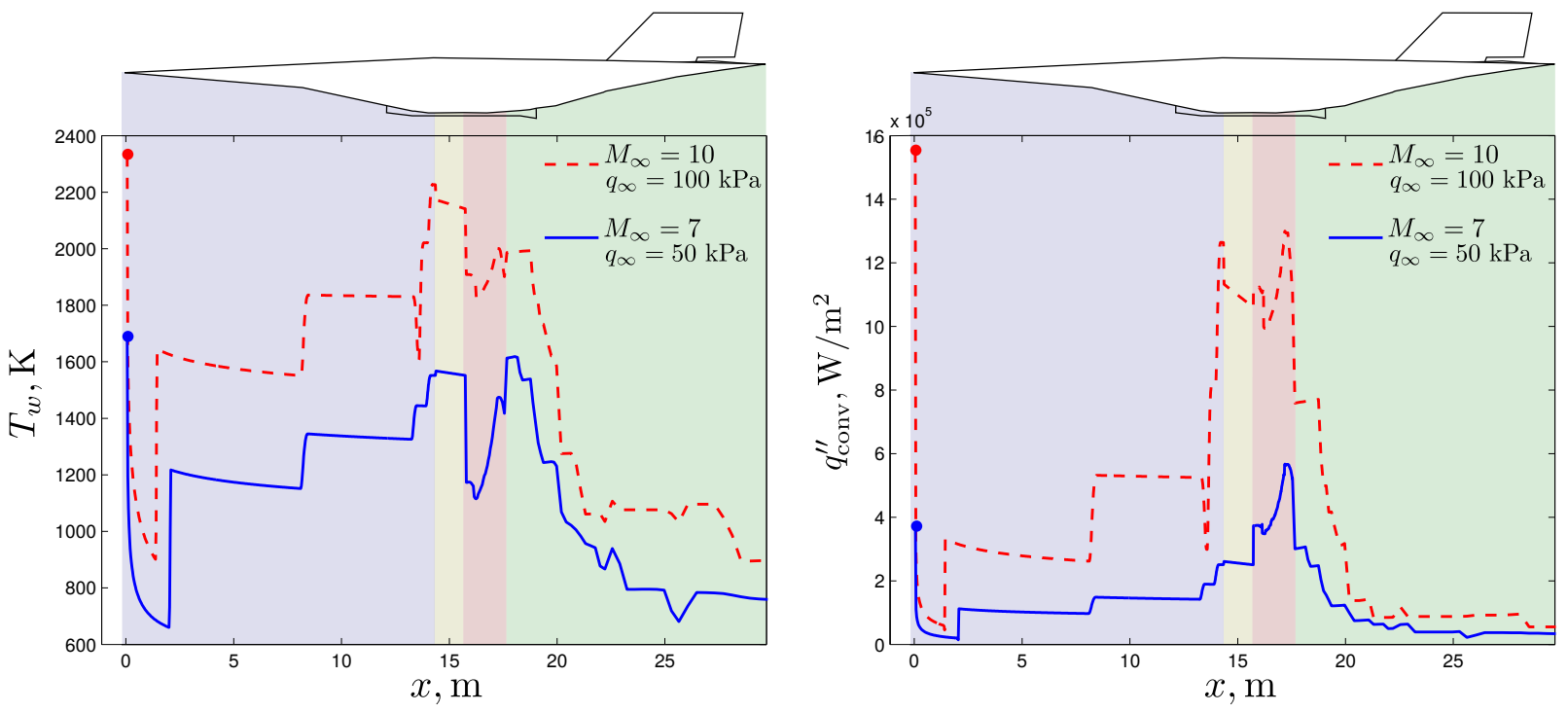

Figure 17. Wall temperature $T_{w}$ and convective heat flux $q_{\text {conv }}^{\prime \prime}$ along propulsive flow-path. Two cruise conditions analyzed: $M_{\infty}=10, q_{\infty}=100 \mathrm{kPa}$ and $M_{\infty}=7, q_{\infty}=50 \mathrm{kPa}$. Results shown are after 40 minuets of cruise.

a)
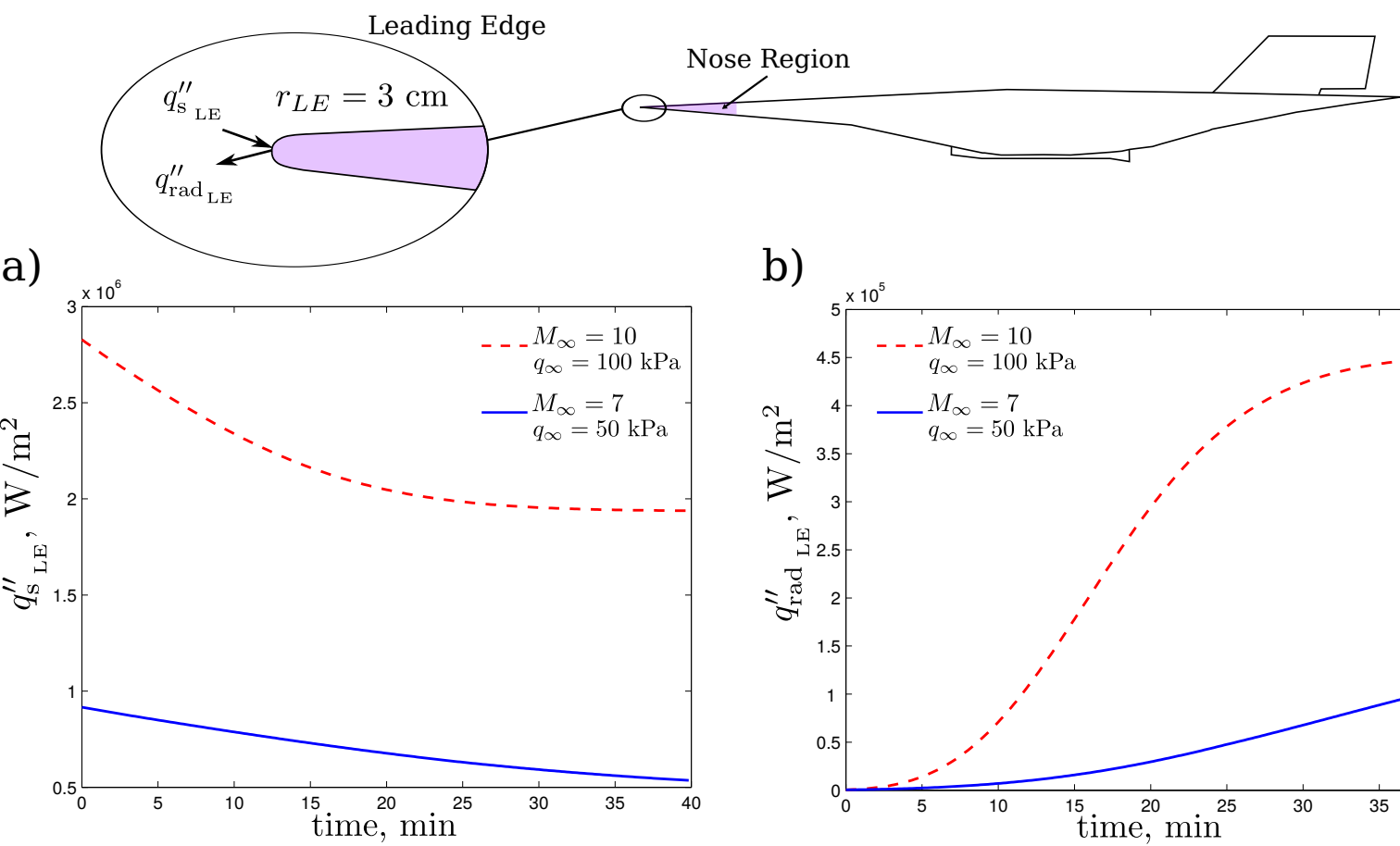

b)

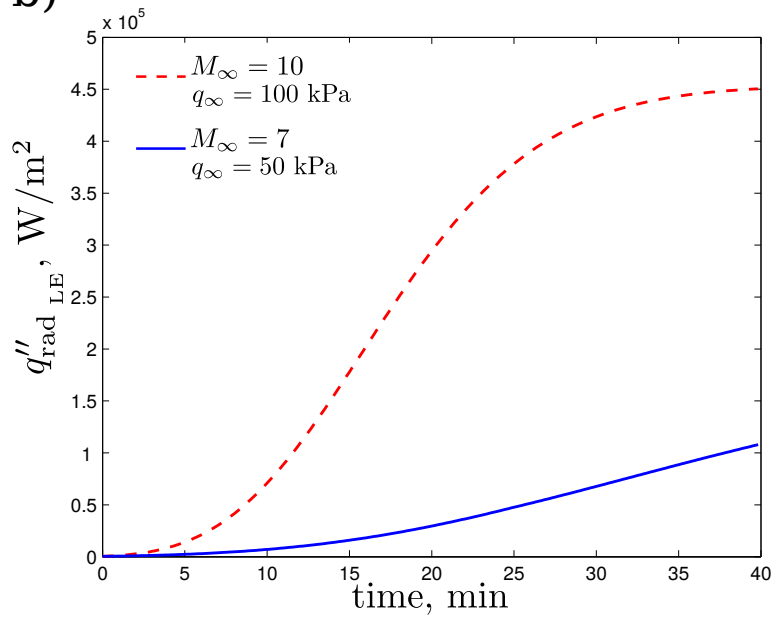

Figure 18. Leading edge heat flux versus time for two trimmed flight conditions: $M_{\infty}=10, q_{\infty}=100 \mathrm{kPa}$ and $M_{\infty}=7, q_{\infty}=50 \mathrm{kPa}$. a) Leading edge stagnation point heat flux $q_{s_{L E}}^{\prime \prime}$ versus time, b) leading edge radiative heat flux $q_{\mathrm{rad}_{L E}}^{\prime \prime}$ versus time. 


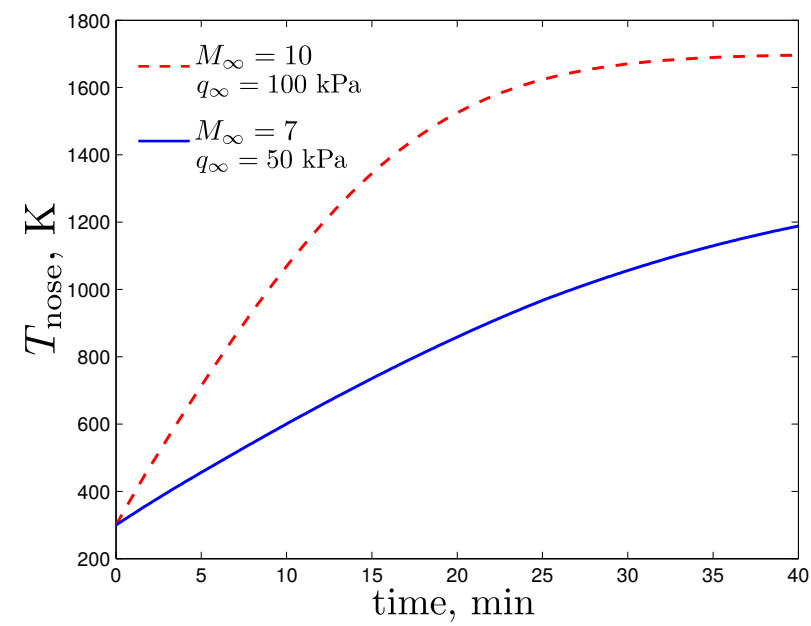

Figure 19. Increase in temperature of the nose region over time for two cruise flight conditions.

\section{Active Thermal Protection System}

As discussed in Part $\mathrm{C}$ of Section IV, the liquid hydrogen fuel acts as the cooling agent within the heat exchangers in the active cooling system. A schematic of the cooling channels surrounding the combustor is shown in Fig. 20. Sever parameters effect the performance of the heat exchangers. The number of cooling channels effects the total contact area between the heat exchangers and the combustor wall, and hence effects the total amount of energy transfered away from the walls and into the hydrogen fuel. Other important heat exchanger parameters include the cooling channel hydraulic diameter $D_{C}$ and cross sectional area $A$ shown in Fig. 21. As seen in Eqs. 20 and 21, the heat exchanger heat flux $q_{\mathrm{HEX}}^{\prime \prime}$ is inversely proportional to both $D_{C}$ and $A$.

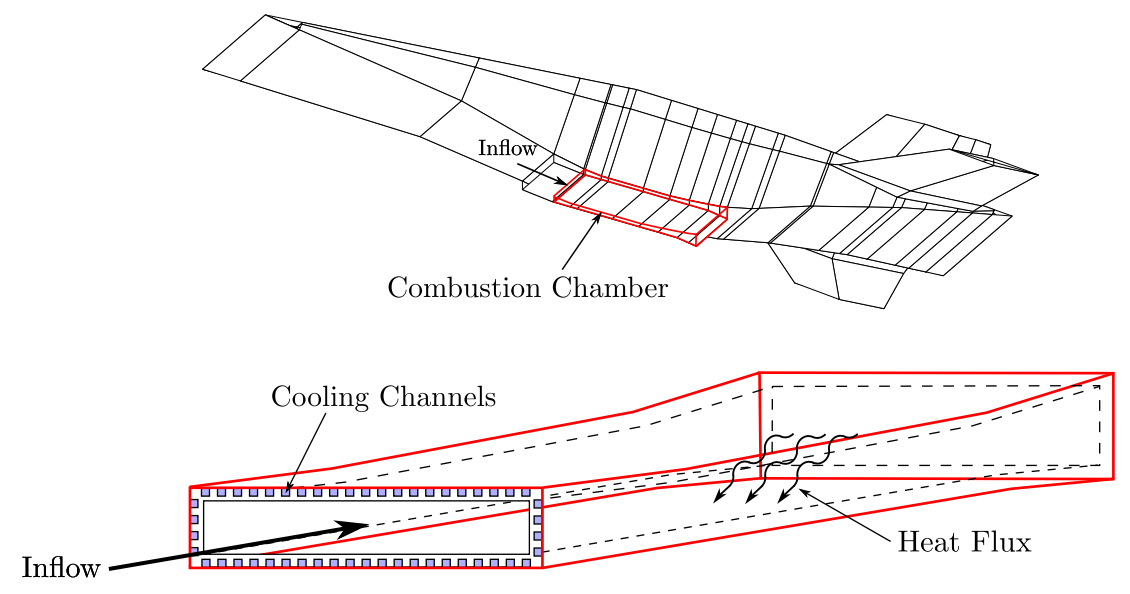

Figure 20. Schematic of the active cooling channels surrounding the vehicle combustor.

The results from Part $\mathrm{B}$ of the current section show that the combustor walls experience the most critical heating. To demonstrate the effectiveness of the heat exchanger in reducing the combustor wall temperature, a cruise simulation is performed at the same conditions as the case presented in Fig. 13 $\left(M_{\infty}=7\right.$ and $\left.q_{\infty}=50 \mathrm{kPa}\right)$. For the results presented in Fig. 13, only a passive TPS is utilized and a maximum temperature of approximately $1700 \mathrm{~K}$ occurs at the combustor wall outer surface at $x=17 \mathrm{~m}$. Figure 22 shows the combustor wall temperature profile at the same location $(x=17 \mathrm{~m})$ when active cooling 


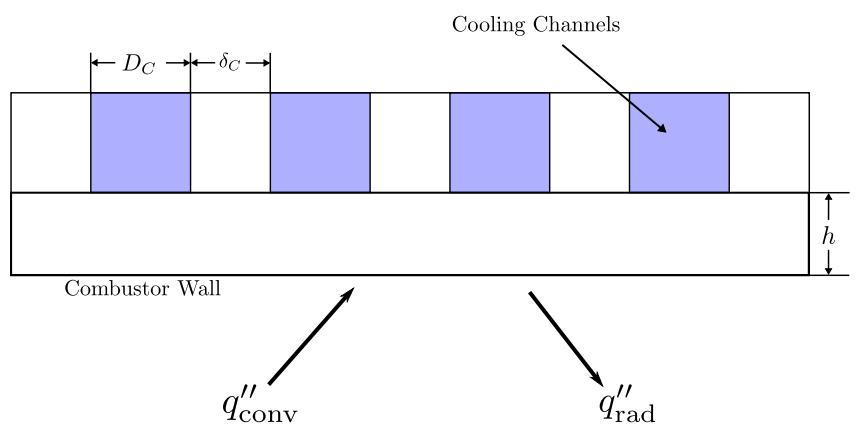

Figure 21. Schematic showing active cooling channel geometry.

is employed. The results in Fig. 22 are for a case with 40 cooling channels each with a hydraulic diameter of $0.1 \mathrm{~m}$ and a coolant mass flow rate of $3 \mathrm{~kg} / \mathrm{s}$ per channel. Two combustor wall thickness are presented in Fig. $22, h_{\text {comb }}=12 \mathrm{~mm}$ and $h_{\text {comb }}=60 \mathrm{~mm}$. In both cases, the maximum wall temperature is reduced from the passive only TPS case (from $1700 \mathrm{~K}$ down to approximately $1300 \mathrm{~K}$ for $h_{\text {comb }}=12 \mathrm{~mm}$ and down to approximately $1400 \mathrm{~K}$ for $h_{\mathrm{comb}}=40 \mathrm{~mm}$ ). Figure 22 also reveals that a thinner combustor wall results in lower temperature.

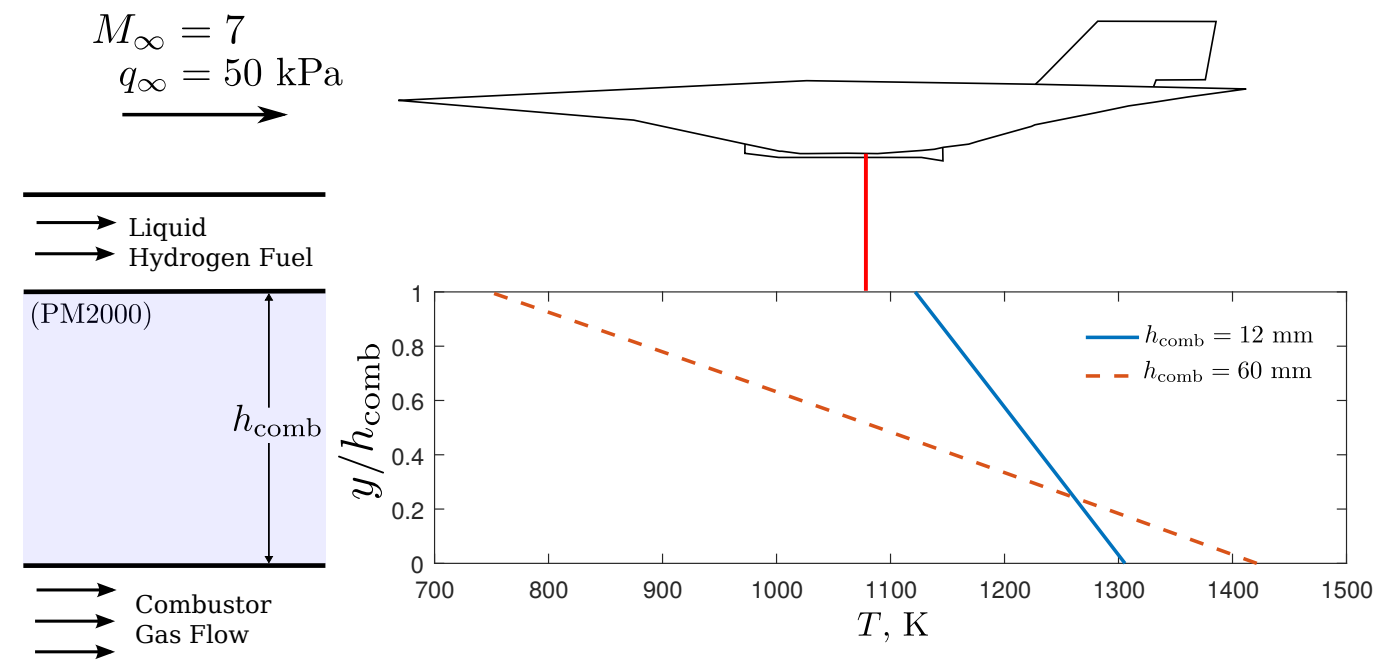

Figure 22. Combustor wall temperature distribution with active cooling. Results shown are after 40 minutes at a trimmed flight condition of $M_{\infty}=7$ and $q_{\infty}=50 \mathrm{kPa}$. Two combustor thicknesses are shown: $h_{\mathrm{comb}}=12$ $\mathrm{mm}$ and $h_{\mathrm{comb}}=160 \mathrm{~mm}$. The results are presented at $x=17 \mathrm{~m}$.

The temperature distribution of the hydrogen fuel $T_{F}$ through the heat exchanger and the cooling channel wall temperature $T_{w c}$ are shown in Fig. 23 for two different times at the same conditions as just described. At the initial time $t=0, T_{F}$ is uniform and equal to the initial temperature of the fuel tank $(60 \mathrm{~K})$. The cooling channel wall is also initially uniform and equal to the combustor wall initial temperature (300 $\mathrm{K})$. After 20 minuets, the fuel temperature increases only modestly to about $70 \mathrm{~K}$. A much lager larger temperature increase occurs at cooling channel wall. As the liquid hydrogen passes through the cooling channel and is heated, a portion of the fuel is then expelled through the combustor while the remaining portion is recirculated. As the heated fuel is recirculated, the temperature of the fuel within the fuel tank rises. Figure 24 shows the increase in the fuel tank temperature over time; after 40 minuets, the fuel tank temperature is approximately doubled to $120 \mathrm{~K}$. According to Ref. 31, these temperatures are common for storage of liquid hydrogen in cryogenic capable pressure vessels. 


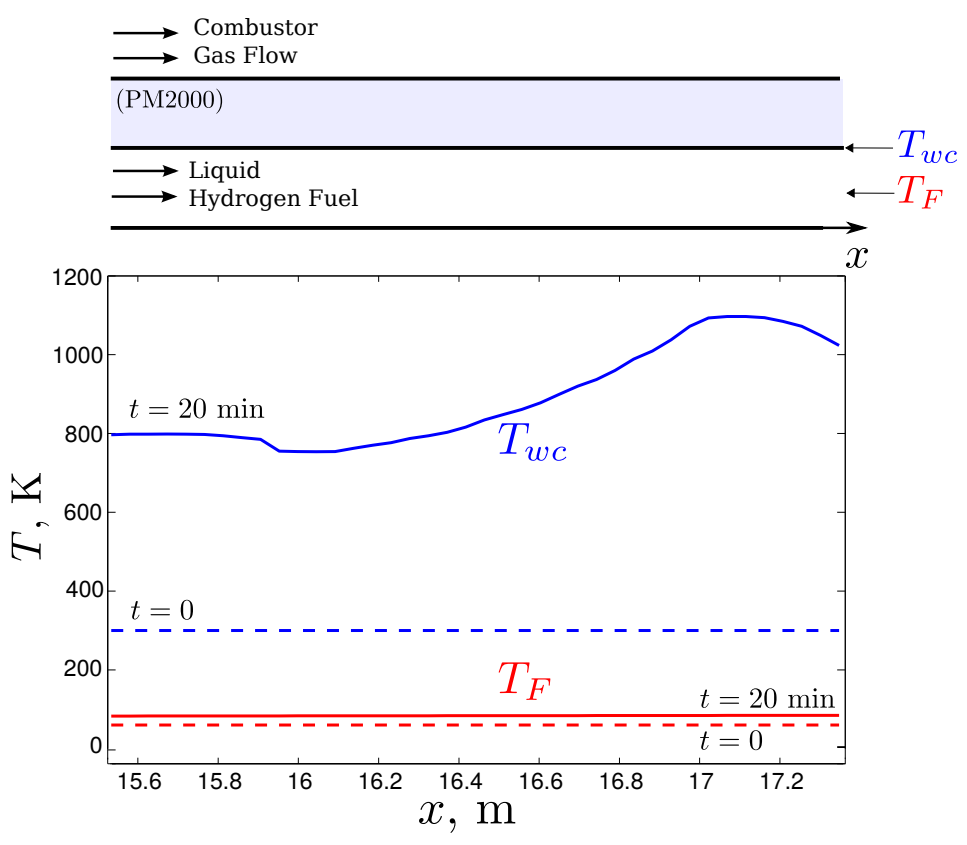

Figure 23. Temperature distribution through the heat exchanger at a trimmed flight condition of $M_{\infty}=7$ and $q_{\infty}=50 \mathrm{kPa}$. Mass flow rate of fuel is $3 \mathrm{~kg} / \mathrm{s}$ and the hydraulic diameter of the channel is $D_{C}=0.1 \mathrm{~m}$. The thickness of the combustion chamber wall is $h_{\mathrm{comb}}=12 \mathrm{~cm}$.

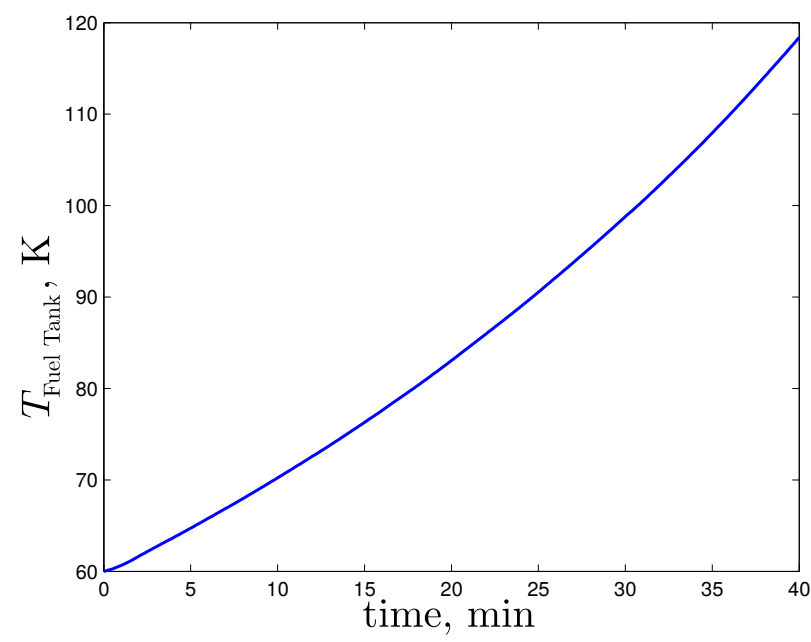

Figure 24. Increase in fuel tank temperature over time for a trimmed flight condition of $M_{\infty}=7$ and $q_{\infty}=50$ $\mathrm{kPa}$. Mass flow rate of fuel per cooling channel is $3 \mathrm{~kg} / \mathrm{s}$ and there are 40 channels around the combustor. The hydraulic diameter of each channel is $D_{C}=0.1 \mathrm{~m}$ and the thickness of the combustion chamber wall is $h_{\mathrm{comb}}=12 \mathrm{~cm}$. 


\section{Conclusions}

Aerodynamic heating in hypersonic vehicles is severe and continued efforts to model heating and thermal protection for design and optimization purposes are required. Design and optimization efforts necessitate the use of reduced-order models. A literature review revealed a lack of comprehensive reduced-order models for scramjet-powered vehicles considering aerodynamic heating and both active and passive thermal protection systems.

Efficient aerodynamic heating and radiative cooling models are added to MASIV, an already existing reduced-order model of a hydrogen-fueled scramjet vehicle. A passive Thermal Protection System (TPS) model is also added, consisting of three layers: 1) a radiation shield (on the side exposed to the air), 2) insulation and 3) titanium skin. The results show that the propulsion system flow-path (consisting of the inlet, isolator, combustor and nozzle) experiences more severe heating than the remaining vehicle external surface (compare Fig. 9 to Fig. 10). The magnitude of the heating on the vehicle external surface indicates that the passive TPS alone will likely suffice in that region.

Stagnation point heating at the vehicle leading edge is also modeled. As seen in Figs. 10 and 17, the analysis indicates that the largest heat flux values occur at the leading edge and through the isolator and combustor. However, while the stagnation point heat flux is the same order of magnitude as the isolator/combustor heating, the leading edge surface area is small compared to the isolator/combustor. The large heat flux in the isolator and combustor likely requires active cooling. An active cooling model, utilizing the hydrogen fuel as the cooling agent, is added to MASIV. As shown in Fig. 22, the active cooling system can reduce the combustor wall temperature to a reasonable value compared to the passive only TPS case. Figure 22 also provides insight into TPS design considerations; within the active cooling system, additional wall thickness does help to alleviate the wall temperatures.

Other important design considerations can also be gleaned from the results. The flight trajectory has a large impact on the vehicle heat flux. In particular, lower altitudes result in higher heating (due to the large increase in free-stream density at lower altitudes). Also, larger Mach numbers result in higher heating due to increased free-stream velocity (see Figs. 10, 12, 13). Note that while $q_{\text {conv }}^{\prime \prime} \propto \rho_{e}^{1 / 2}$ and $q_{\text {conv }}^{\prime \prime} \propto u_{e}^{1 / 2}$, the percent changes in $\rho_{e}$ are larger than the present changes in $u_{e}$ leading to density changes (at varying altitudes and though inlet shocks) being a driving parameter.

The results in Figs 14 show that the radiation shield reaches a maximum temperature very rapidly but the titanium skin continues to increase over time. Also, as seen in Fig. 15, varying the radiation shield thickness has very little effect on the maximum temperature within the radiation shield. For design considerations, it is best to make the radiation shield as thin as possible. Additionally, because the radiation shield temperature rises rapidly, heating-related operability limits are required for the vehicle temperatures to remain below their failure temperatures. On the other hand, increasing the thickness of the titanium skin does lower the maximum temperature within the skin (the skin acts as a heat sink). For design considerations, the skin thickness can be increased in the most critical heating regions (i.e. the inlet). Because the skin temperature gradually increases, a time limit is also required in addition to the operability limits.

Analysis of the overall effect of heating is highly mission dependent, as the vehicle trajectory impacts the convective heating to the surface. The size of the thermal protection system impacts the vehicle weight which in turn impacts the orientation, trim and engine thrust required. Furthermore, there is a trade-off between heating to the thermal protection system and heating to the fuel in the active cooling system. A larger thermal protection system would results in less fuel heating (perhaps extending the vehicle endurance) but would add to the weight, which could actually lead to a reduction in vehicle endurance depending on vehicle design restrictions. There is also a question as to which temperature limit is reached first, the skin or the fuel. The MASIV code, along with the added heat transfer and thermal protection system models, provide an efficient tool with adequate fidelity to properly design and optimize for the vehicle TPS along with the flight trajectory.

\section{References}

${ }^{1}$ J. E. Johnson, R. P. Starkey, and M. J. Lewis, "Aerothermodynamic optimization of reentry heat shield shapes for a crew exploration vehicle," Journal of Spacecraft and Rockets, vol. 44, no. 4, pp. 849-859, 2007.

${ }^{2} \mathrm{M}$. Bolender and D. Doman, "Modeling unsteady heating effects on the structural dynamics of a hypersonic vehicle," AIAA Paper, vol. 6646, p. 2006, 2006. 
${ }^{3}$ S. Rizvi, L. He, and D. Xu, "Optimal trajectory and heat load analysis of different shape lifting reentry vehicles for medium range application," Defence Technology, vol. 11, no. 4, pp. 350-361, 2015.

${ }^{4}$ S. T. Rizvi, H. Linshu, and X. Dajun, "Optimal trajectory analysis of hypersonic boost-glide waverider with heat load constraint," Aircraft Engineering and Aerospace Technology: An International Journal, vol. 87, no. 1, pp. 67-78, 2015.

${ }^{5}$ V. G. Tormo and V. C. Serghides, "Initial sizing and reentry trajectory design methodologies for dual-mode-propulsion reusable aerospace vehicles," Journal of Spacecraft and Rockets, vol. 44, no. 5, pp. 1038-1050, 2007.

${ }^{6}$ D. Zhang, S. Tang, and J. Che, "Concurrent subspace design optimization and analysis of hypersonic vehicles based on response surface models," Aerospace Science and Technology, vol. 42, pp. 39-49, 2015.

${ }^{7}$ C. Gogu, T. Matsumura, R. T. Haftka, and A. V. Rao, "Aeroassisted orbital transfer trajectory optimization considering thermal protection system mass," Journal of Guidance, Control, and Dynamics, vol. 32, no. 3, pp. 927-938, 2009.

${ }^{8}$ W. Bao, X. Li, J. Qin, W. Zhou, and D. Yu, "Efficient utilization of heat sink of hydrocarbon fuel for regeneratively cooled scramjet," Applied Thermal Engineering, vol. 33, pp. 208-218, 2012.

${ }^{9}$ C. Zhang, J. Qin, Q. Yang, S. Zhang, and W. Bao, "Design and heat transfer characteristics analysis of combined active and passive thermal protection system for hydrogen fueled scramjet," International Journal of Hydrogen Energy, vol. 40, no. 1, pp. 675-682, 2015.

${ }^{10}$ D. B. Doman, "Optimal cruise altitude for aircraft thermal management," Journal of Guidance, Control, and Dynamics, vol. 38, no. 11, pp. 2084-2095, 2015.

${ }^{11}$ N. Gascoin, P. Gillard, E. Dufour, and Y. Touré, "Validation of transient cooling modeling for hypersonic application," Journal of thermophysics and heat transfer, vol. 21, no. 1, pp. 86-94, 2007.

${ }^{12}$ R. L. Brown, K. Das, P. G. Cizmas, and J. D. Whitcomb, "Numerical investigation of actively cooled structures in hypersonic flow," Journal of Aircraft, vol. 51, no. 5, pp. 1522-1531, 2014.

${ }^{13}$ D. K. Huzel, Modern engineering for design of liquid-propellant rocket engines, vol. 147. AIAA, 1992.

${ }^{14}$ D. B. Doman, "Fuel flow control for extending aircraft thermal endurance part i: Underlying principles," in $A I A A$ Guidance, Navigation, and Control Conference, p. 1621, 2016.

${ }^{15}$ R. P. Starkey, D. D. Liu, P.-C. Chen, A. Sengupta, K.-T. Chang, and F. Rankins, "Integrated aero-servo-thermo-propulsoelasticity (astpe) methodology for hypersonic scramjet vehicle design/analysis," AIAA Paper, vol. 1122, 2010.

${ }^{16}$ D. J. Dalle, S. M. Torrez, J. F. Driscoll, M. A. Bolender, and K. G. Bowcutt, "Minimum-fuel ascent of a hypersonic vehicle using surrogate optimization," Journal of Aircraft, vol. 51, no. 6, pp. 1973-1986, 2014.

${ }^{17}$ D. J. Dalle, J. F. Driscoll, and S. M. Torrez, "Ascent trajectories of hypersonic aircraft: Operability limits due to engine unstart," Journal of Aircraft, vol. 52, no. 4, pp. 1345-1354, 2014.

${ }^{18}$ D. J. Dalle, M. L. Fotia, and J. F. Driscoll, "Reduced-order modeling of two-dimensional supersonic flows with applications to scramjet inlets," Journal of Propulsion and Power, vol. 26, no. 3, pp. 545-555, 2010.

${ }^{19}$ S. M. Torrez, J. F. Driscoll, M. Ihme, and M. L. Fotia, "Reduced-order modeling of turbulent reacting flows with application to ramjets and scramjets," Journal of propulsion and power, vol. 27, no. 2, pp. 371-382, 2011.

${ }^{20}$ S. M. Torrez, D. J. Dalle, and J. F. Driscoll, "New method for computing performance of choked reacting flows and ram-to-scram transition," Journal of Propulsion and Power, vol. 29, no. 2, pp. 433-445, 2013.

${ }^{21}$ D. Dalle, S. M. Torrez, and J. F. Driscoll, "Rapid analysis of scramjet and linear plug nozzles," Journal of Propulsion and Power, vol. 28, no. 3, pp. 545-555, 2012.

${ }^{22}$ N. Lamorte, P. P. Friedmann, D. J. Dalle, S. M. Torrez, and J. F. Driscoll, "Uncertainty propagation in integrated airframe-propulsion system analysis for hypersonic vehicles," Journal of Propulsion and Power, vol. 31, no. 1, pp. 54-68, 2014.

${ }^{23}$ M. A. Bolender and D. B. Doman, "Nonlinear longitudinal dynamical model of an air-breathing hypersonic vehicle," Journal of Spacecraft and Rockets, vol. 44, no. 2, pp. 374-387, 2007.

${ }^{24}$ F. M. White, Viscous fluid flow. McGraw-Hill series in mechanical engineering, New York: McGraw-Hill, 1991.

${ }^{25}$ M. E. Tauber, "A review of high-speed, convective, heat-transfer computation methods," 1989.

${ }^{26}$ C. D. Scott, R. Ried, R. Maraia, C.-P. Li, and S. Derry, "An aotv aeroheating and thermal protection study," 1984.

${ }^{27}$ R. D. McCarty, J. Hord, and H. Roder, "Selected properties of hydrogen (engineering design data)," tech. rep., National Engineering Lab.(NBS), Boulder, CO (USA), 1981.

${ }^{28}$ K. G. Bowcutt, "Multidisciplinary optimization of airbreathing hypersonic vehicles," Journal of Propulsion and Power, vol. 17 , no. 6 , pp. $1184-1190,2001$.

${ }^{29}$ C. W. Ohlhorst, D. E. Glass, W. Bruce, M. C. Lindell, W. L. Vaughn, R. Smith, R. Dirling Jr, P. Hogenson, J. Nichols, N. Risner, et al., "Development of x-43a mach 10 leading edges," in 56th International Astronautical Congress, Fukuoka, Japan, 2005 .

${ }^{30}$ C. W. Ohlhorst, W. L. Vaughn, P. O. Ransone, and H.-T. Tsou, Thermal conductivity database of various structural carbon-carbon composite materials, vol. 4787. National Aeronautics and Space Administration, Langley Research Center, 1997.

${ }^{31}$ S. M. Aceves, F. Espinosa-Loza, E. Ledesma-Orozco, T. O. Ross, A. H. Weisberg, T. C. Brunner, and O. Kircher, "Highdensity automotive hydrogen storage with cryogenic capable pressure vessels," International Journal of Hydrogen Energy, vol. 35 , no. 3 , pp. 1219-1226, 2010 . 